\title{
La muerte individualizada en la vida cotidiana y en la literatura medieval castellana (siglo XI-XV)
}

\author{
The individualized death in the daily life, and in the Castilian \\ middle ages literature (XI-XV centuries)
}

\author{
FÉLIx A. Ferrer García*
}

\begin{abstract}
RESUMEN
Emprender un estudio parcial sobre el tema de la muerte obedece a un interés creciente por los problemas planteados por la historiografía de las mentalidades y a un intento de analizar una proposición tan interesante como la actitud de los hombres medievales ante un hecho que existe y se manifiesta por sí mismo, sin necesidad de formas conscientes o de reacciones instintivas, pero que, singularmente, comporta un tema lógico y utópico, un proceso de mitificación y otro de dogmatización. Las implicaciones teoréticas de una «ideología de la muerte» interesan más como instrumentos al servicio de un poder que como elementos incorporados a unos sentimientos en la Castilla medieval. Sorprende más la posibilidad de dominio sobre un pueblo a través de una estructura ideológica, teológica $y$, en parte, ilusoria que las probables muestras de solidaridad social alrededor de unos sentimientos de inseguridad en la vida y angustia ante la muerte. A lo largo de varios siglos, del XI al $X V$, las respuestas de los castellanos variaron sustancialmente ante una transición vida-muerte que a todos
\end{abstract}

\section{ABSTRACT}

To undertake a partial study on the subject of the death obeys to an increasing interest about the problems created by the historiography of the mentalities and to an attempt to analyze an interesting proposal as the attitude of the medieval men towards a fact that exists and it is expressed by itself, with no need of conscious forms or instinctive reactions, but that, singularly, deals with a logical and utopian subject, a mythical process and another of dogmatism. The theoretical implications of an «ideology of the death» are interesting more like instruments to serve the power than like elements joint to feelings in medieval Castile. It surprises more the possibility of dominating people through a theological ideological structure, and, partly, false than the probable proof of social solidarity around feelings of insecurity in life and distresses about death. Throughout history, from XI to XV century, the attitude of Castilians substantially varied facing a transition lifedeath that equalized or resign everyone, not by the own individual will, but by a defence mechanism of society that, sometimes, contemplated life like a slow

* UNED (C.A. Ávila)-Institución «Gran Duque de Alba». 
igualaba o conformaba no por la propia voluntad del individuo, sino por un mecanismo de defensa de la sociedad que, en ocasiones, contemplaba la vida como un lento camino hacia la muerte o como una "sub-muerte» misma, mostrándose su sentido como instrumento y signo de un orden jerárquico y una ortodoxia concreta frente a la rica y variada existencia de culturas en la sociedad medieval.

\section{PALABRAS CLAVE:}

Libro de Buen Amor»; parodia; cultura popular; didactismo medieval; «muerte domada»; "muerte propia»; resignación cristiana; enfermedad; viático; velatorio; testamento; ideal caballeresco; fama/honra. way towards death or like a "sub-death" itself, showing their sense as an instrument and sign of a hierarchical order and an specific orthodoxy versus the rich and varied existence of different cultures in the medieval society.

\section{KEY WORDS}

«Book of Good Love»; parody; popular culture; medieval didactic; «tamed death»; "own death»; Christian resignation; disease; viaticum; wake; testament; chivalrous ideal; reputation/honour.

Noli altum sapere, sed time (Rom. 11, 20). El falso orgullo en torno al conocimiento prohibido fue irremediablemente condenado por la Iglesia a lo largo de la Edad Media. Alejadas de su propio contexto, las palabras de san Pablo fueron citadas durante siglos por los escritores eclesiásticos como una prueba de autoridad ante cualquier intento de vencer los límites del intelectual humano. «La primera cosa que mandamos e queremos que sea tenuda e guardada sobre todas las cosas es esta: que todo christiano se esfuerçe de connosçer a Dios. Ca pues quel conosciere, entonces sabrá amar e temer, e Dios amará otrossí a él et auerle a merced» (Primera Partida, II, Iª). Ícaro caído del cielo y Prometeo castigado por robar el fuego divino se asimilaron con aquellos que contraponían la vida cotidiana a un sentido cerrado ante un hecho ineludible como la muerte. Platón afirmó que la filosofía era una meditación sobre la muerte, mientras que Cicerón escribió después que toda vida filosófica es una commentatio mortis. Griegos y romanos se tomaron muy en serio la muerte: no se dudaba que el hombre estuviera sometido a ella. Y, no obstante, las ideas de sus religiosidades no son respuestas a preguntas, sino que expresan la postura del hombre antiguo ante la realidad de la muerte como tal.

Siglos más tarde, la inquietud del hombre por la muerte se plasmó maravillosamente, con unos desarrollos extraordinarios, en el "Triunfo de la Muerte» (Museo del Prado), de Pieter Brueghel el Viejo, en donde aparece un tema característico de la iconografía de los siglos XIV y XV. En el cuadro del pintor flamenco la afirmación constante de la muerte asume su plena realidad sin ninguna idealización, sin ninguna protesta de tipo social. Únicamente en el intento del juglar por es- 
conderse bajo la mesa del banquete se muestra un tono burlón, un leve sarcasmo hacia la muerte. Un dualismo constante se mantiene en el período medieval en torno al fin de la vida, el inicio de la muerte. Hieronimus van Aeken, «El Bosco», se inspiró parcialmente en los salmos de san Agustín de Hipona y en los comentarios de san Gregorio sobre el «Libro de Job» para representar «El Jardín de las Delicias» (Museo del Prado). Con un trasfondo procedente de la secta del Libre Espíritu, elaboró tres tablas que vienen a resumir los tres momentos de paso en la vida y en el mundo, es decir, la "creación» (primera tabla), con formas fantásticas y de escasa entidad corpórea, con la creación de la mujer por la divinidad y ante el hombre. El «Jardín» (tabla central), con diversos juegos y símbolos, señalándose en el fondo una laguna en la que desembocan los cuatro ríos del Paraíso. Es la realidad después de la creación de un mundo dominado por los vicios y entregado a la lujuria, una visión de la amoralidad de una tierra encadenada a los sentidos corporales. El carácter dramático se acentúa ya en la última tabla, con un juego de luces y tinieblas: la muerte conduce inexorablemente al infierno, a sus horrores y a la condenación eterna. Es el extremismo ante la muerte de una actitud mientras dura la vida, pero ¿real o grotesca?

Cuando Hans Baldung von Grien (1484-1545) realiza su obra titulada «Las edades y la Muerte" (Museo del Prado), ésta adquiere una forma humana totalmente personificada, un esqueleto con las carnes en descomposición, putrefactas. En una mano tiene un reloj de arena, en la otra una lanza rota que, en su extremo, toca a un niño, representación de la primera edad. Un búho es el compañero inseparable de la muerte, al igual que el cuervo negro en el planto a la Trotaconventos (LBA, estr. 1529-1530), o como en algunos romances en los que la muerte se anuncia por medio de las aves de rapiña. La mujer joven, segunda edad, está unida a la vieja, que, a su vez, es agarrada por la Muerte. El paisaje del cuadro está desnudo, completamente desolado. La muerte y la destrucción se han cebado sobre árboles, casas y campos. Al fondo, escenas violentas, incendios y grietas en el suelo. El diablo arrastra a un hombre por las aguas. El cielo es plomizo, grisáceo, resaltando la luna llena y, un poco más abajo siguiendo una línea diagonal a la luna, aparece la figura de Cristo crucificado.

Las edades y la Muerte están perfectamente representadas. Son comprensibles para los fieles en el «otoño de la Edad Media». Se nace unido a la muerte y la escenificación de la vida es casi un círculo cerrado y continuo en el que la joven es agarrada por la vieja, ésta por una Muerte que se une al nacimiento con su arma. Así pues, dos elementos iconográficos destacados, si bien menos llamativos para el espectador, se presentan en obra de Hans Baldung, la luna y Cristo, dos polos cultuales que estarán presentes en la cultura popular medieval del mundo occidental. La Luna, en los antiguos cultos del Principio Femenino, es la «vieja mujer», una ficción y una creencia importantes en los medios rurales, al igual que en Juan Ruiz la Trotaconventos se asociará con la sabiduría femenina: «mataste a mi vieja» (estr. 1520b). De igual manera, Cristo actúa como un Eros masculino en el Libro de Buen Amor, resaltando tanto el principio de fecundidad como toda una tra- 
dición evangélica que le presenta como el héroe que salva a santos y personajes bíblicos, a patriarcas y hombres escogidos (estr. 1556-1564).

Más que un discurso rectilíneo, este artículo centrado en el sentido de la muerte en la Edad Media castellana trata de tejer una espiral en torno al planto que Juan Ruiz, el Arcipreste de Hita, dedica a la Trotaconventos, analizando tanto las influencias literarias como los resortes mentales y culturales que son recogidos por una tradición a mediados del siglo XIV, sin olvidar las transformaciones que en los años siguientes, a raíz del colapso demográfico originado por la Peste Negra se producirán tanto en las prácticas cotidianas relacionadas con la actividad necrolátrica como en la alta literatura de los siglos finales medievales. Los textos oficiales muestran las costumbres, formas y maneras de actuación ante los acontecimientos de la vida cotidiana, hechos supuestamente anómalos (el homicidio, el suicidio, la violación), incomprensibles en su apariencia (la enfermedad, la muerte), su reglamentación, desarrollo, censura y prohibición, la exigencia de los poderes políticos y religiosos por encauzar debidamente las manifestaciones de dolor que tales modos provocaban. Los textos literarios, por su lado, explican subjetivamente al lector los sentimientos, las percepciones y las emociones (las mentalidades) que la muerte, por ejemplo, provocaban en aquellos individuos que manejaban la lengua y, además, trataban de difundirla. Aunque el fallecimiento del hombre no era exclusivo de un determinado grupo social, los imperativos morales, teológicos, antropológicos y políticos resaltaban las diversas y diferenciadas cualidades de un mismo fenómeno. De ahí el interés por acercarse al sentido de la muerte en un período algo tardío de la Edad Media, los siglos XIV y XV, en las palabras y miradas atentas de algunos escritores.

Ciertamente, la historiografía europea se ha preocupado por el tema de las actitudes del hombre ante la muerte, especialmente en Europa occidental desde la Segunda Guerra Mundial y en España desde hace unos veinte o veinticinco años siguiendo los modelos epistemológicos franceses. En un principio imperaban los planteamientos iniciales de la escuela francesa de los «Annales», es decir, unos estados metodológicos que promovían la invasión total del historiador en los terrenos de los comportamientos de los hombres ante la vida y la muerte y, en consecuencia, un acaparamiento por parte del investigador de toda una serie de disciplinas sociales que, en realidad, eran inabarcables a su propia tarea. Lucien Febvre, al reseñar una obra de Edgar Morin, proponía la realización de una cartografía de la muerte, un estudio sobre las costumbres y modas de los sepulcros, ritos y creencias sobre el paso de la vida terrenal al más allá. De una forma u otra, varios autores siguieron de cerca estas indicaciones ${ }^{1}$. Alberto Tenenti, que ese mismo año de 1952 hacía una ejemplar interpretación sobre el mismo tema en el arte, entendía que la muerte era ante todo una acontecimiento esencial en la vida de las sociedades, en tanto que significaba el fin del cuerpo y el paso a la vida eterna ${ }^{2}$.

1 L. FEBVRE, «La mort dans l'Histoire», Annales E.S.C., VII (1952), pp. 223-226. E. MORIN, L'homme et la mort dans l'Histoire, Paris, 1951.

2 A. TENENTI, La vie et la mort à travers l'art du XV siècle, Paris, 1952; II senso della morte e l'amore della vita nel Rinascimento (Francie e Italia), Torino, 1957. 
Sin embargo, el problema que presenta cualquier actitud ante la muerte es más complicado de lo que parece. En primer lugar, hay que considerar que en la mayoría de los casos los historiadores han utilizado en sus estudios seriales un único tipo de documentos, testamentos hológrafos en el caso de Pierre Chaunu ${ }^{3}$, mientras que en otras ocasiones no se consideraban los discursos ideológicos y eclesiásticos (Philippe Ariès), o no se establecía una relación estrecha entre las categorías temáticas y las fuentes escogidas, siendo éste el principal problema del francés François Lebrun ${ }^{4}$, a pesar de sus aportaciones que dejan entrever cómo las actitudes ante la muerte sufren de una manera muy atenuada los cambios, las evoluciones y, especialmente, las reactivaciones culturales de la época renacentista. Lebrun muestra, en resumen, una sociedad (la angevina) muy marcada por la religión y con unas actitudes muy tradicionales ante la enfermedad y la muerte: la enfermedad es deseada por Dios, es un signo y una advertencia, un castigo de la divinidad. Es preciso prepararse para un buen morir, pues hay una muerte repentina. Las armas contra la enfermedad se limitan a la oración, la invocación mariana y los intercesores ante Dios.

¿Se puede decir que hay un marcado cambio en el sentido de la muerte entre la Edad Media y el racionalista siglo XVIII? A un nivel divulgativo la respuesta es afirmativa. Las "Danzas de la Muerte» y lo macabro, el arte de bien morir, el ars moriendi, la agonía y el tránsito del creyente de la tierra al trasmundo así lo atestiguan. Sin embargo, para Lebrun, el cambio definitivo viene dado por una «desacralización de la enfermedad y de la muerte" a finales del siglo XVIII, una nueva actitud ante los fallecimientos de los niños en la cuna, frente a la enfermedad y la epidemia. Con el edicto francés de 1776 se prohibió la inhumación en las iglesias y se pasó al entierro en los cementerios extramuros: hay una «desocialización de la muerte» en el ochenta y nueve de la Revolución Francesa (P. Chaunu). En otro sentido y para otro marco histórico, el estudio de los comportamientos ante la muerte refleja su integración en el marco social y cultural, en la vida cotidiana y en los valores estéticos, las costumbres sexuales y el matrimonio, la condición femenina, el sentimiento de la infancia y de las edades de la vida, el tiempo y el espacio, la naturaleza y el destino, lo sagrado y la religiosidad vivida, el folclore en torno a los aparecidos y la vida de ultratumba, todo ello en un espacio, Montaillou, en el siglo XIII, que se sumerge «en la unidad de base, campesina y popular, que los textos nos han entregado como esencial: la domus o el ostal de cada uno" ${ }^{5}$, donde el sentido de la muerte se caracteriza, primero, por la sociabilidad en torno a los rituales funerarios $y$, segundo, por el fuerte componente del catarismo local que insistía en el problema de la salvación del alma. La angustia del aniquilamiento, como tal, no parecía tener mucha importancia, pues el ideal era no morir solo, ser salvado.

3 P. CHAUNU, La mort à Paris, XVI, XVII, XVIII siècles, Paris, 1978.

4 F. LEBRUN, Les hommes et la mort en Anjou aux XVII et XVIII siècles. Étude de démographie et de psychologie historiques, Paris-La Haye, 1971.

5 E. LE ROY LADURIE, Montaillou, village occitan de 1294 à 1324, Paris, 1975, pp. 612, 324-344. 
Gustosos de señalar unas pautas de conducta frente a la muerte en la historia, los franceses han ejercido una clara influencia en este sentido. Philippe Ariès, en una serie de conferencias pronunciadas en francés en la John Hopkins University ${ }^{6}$, exponía de una forma brillante en cuanto a la diversificación cuatro «formas de muerte» a través de una encuesta "serial» de duración plurisecular. Proponía el autor un esquema global de reconstrucción de las actitudes del hombre europeo ante la muerte, ofreciendo una periodización y una cronología e insistiendo en la existencia en un mismo período, pero en lugares o medios distintos, de diferentes tipos de comportamientos colectivos: «Tamed Death», «One's own Death», «Thy Death» $y$ «Forbidden Death».

Parece difícil establecer con cierta precisión unos estadios evolutivos claros y coherentes con la realidad (imaginada en muchos casos) expresada en todo tipo de documentos. A esto se une un factor importante como es el hecho de la pervivencia de un mundo tradicionalmente cristiano sometido a una serie de adaptaciones culturales que se traducen en una negación por parte de la institución eclesiástica para aceptar las prácticas folclóricas. La Iglesia, en este marco, se oponía a una "cultura popular» a través de la destrucción, por la inutilización, superposición de temas y comportamientos y por la desnaturalización cuando los temas populares cambian de significado por los sustitutos cristianos. La utilización exclusiva de testamentos, bien ológrafos, bien procedentes de la tradición veterotestamentaria, supone el estudio parcial de los comportamientos y actitudes del grupo social que podía y debía realizar esos testamentos, los grupos caballerescos medievales y la nueva burguesía de los siglos XIV y XV. En el caso castellano, la regularización de los bienes en los fueros municipales de aquellos que «morier sin lengua e non feçier manda» refleja una práctica mínima de una imposición jurídica en la mayoría de los casos. Por otra parte, la utilización de una gran documentación testamentaria resulta en ocasiones atractiva cuando se marcan exactamente las pautas teóricas y metodológicas. Michel Vovelle ${ }^{7}$ inscribe el estudio de la muerte en la «larga duración», en la historia serial de las mentalidades propuesta, en particular, por Chaunu. El punto de partida está constituido por el testamento «barroco» de la comarca de Niza, con un formulario muy rico que implica la profusión de lo religioso en todos los actos de la vida y, principalmente, en el umbral de la muerte, en el acto de testar.

El mismo autor, en un artículo publicado en la revista Annales E.S.C. ${ }^{8}$, realiza un planteamiento metodológico insistiendo en las diferentes lecturas sobre el tema de la muerte, situándolas en el terreno de la infraestructura económica y las superestructuras ideológicas. En un intento pedagógico distingue una «muerte experimentada» 0 «soportada», una «muerte vivida» y el propio discurso mortuorio.

${ }^{6} \mathrm{PH}$. ARIĖS, Western attitudes towards Death from the Middle Ages to the Present, Baltimore-London, 1974

7 M. VOVELLE, Piété baroque et déchristianisation en Provence au XVIII siècle. Les attitudes devant la mort d'après les clauses des testaments, Paris, 1973.

${ }^{8} \mathrm{M}$. VOVELLE, «Les attitudes devant la mort: problème de méthode, approches et lectures diferentes", Annales E.S.C., XXXI (1976), pp. 120-132. 
Por otra parte, la producción historiográfica española en torno al tema de la muerte ha crecido espectacularmente en los últimos años, con interesantes aportaciones de Emilio Mitre, Susana Royer, Julio Valdeón, José-Luis Martín y otros autores, siguiendo en muchos casos las pautas francesas sobre el asunto, aunque, eso sí, marcando las nítidas diferencias espaciales y temporales a partir de las fuentes literarias, legales, testamentarias y cronísticas, representando un claro avance en el acercamiento a la «historia de las mentalidades»?.

\section{EL «LIBRO DE BUEN AMOR»}

En este sentido, uno de los aspectos más destacados del Libro de Buen Amor es la presencia casi constante de la muerte. Una obra, por otro lado, disidente dentro del conjunto narrativo-poético castellano de los siglos XIII, XIV y XV. El «buen amor» como sumisión a Dios o como destreza en la relación sexual, confusión esencial para los lectores del Arcipreste. Se articula en el libro esa variabilidad del discurso tradicional con las múltiples lecturas del significante y del significado, pues intellectum tibi dabo, et instruam te in via hac qua gradieris: firmabo super te ocultos meos (estr. 11a-b), sin que sea el autor un simple rústico, sino un componente del conflictivo estamento eclesiástico del siglo XIV, de manera que sus versos no pueden desprenderse de algunas críticas hacia sus superiores clérigos ${ }^{10}$. Su discurso se plasma con grandes dosis de ironía, con una parodia que queda marcada por la ambivalencia del texto cuando se contraponen la exaltación del amor mundano y cierta degradación del sentimiento religioso.

Su punto culminante es el treno o planto que por la Trotaconventos hace el narrador, una parodia de tipo religioso, una versión caricaturizada de una epístola en que san Jerónimo se lamentaba de la muerte de un joven sacerdote (IX, Ad Heliodorum Epitaphium Nepotiani), constituyendo la primera pista para analizar ese sentido de la muerte, un tema que, inevitablemente, va unido a otras constantes del libro como el amor y la influencia de los astros ${ }^{11}$. La única vez que a Juan Ruiz se le escapa una lamentación es, precisamente, cuando muere la Trotaconventos, una alcahueta, «urraca» y mensajera, mujer y vieja identificada con el principio femeni-

9 Algunos ejemplos: J. AURELL y J. PAVÓN (eds.), Ante la muerte. Actitudes, espacios y formas en la España medieval, Pamplona, 2002. E. MITRE FERNÁDEZ, La muerte vencida. Imágenes e historia en el Occidente medieval, 1200-1348, Madrid, 1988. S. ROYEL DE CARDINAL, «Tiempo de morir y tiempo de eternidad", Cuadernos de Historia de España, LXX (1988), pp. 153-180. G. DUBY y otros, La idea y el sentimiento de la muerte en la historia y en el arte de la Edad Media (II), Santiago de Compostela, 1992. J.-L. MARTíN, «El rey ha muerto. ¡Viva el rey!», Hispania, LI (1991), pp. 5-39. C. GONZÁLEZ MíNGUEZ y I. BAZÁN DÍAZ, El discurso legal ante la muerte durante la Edad Media en el nordeste peninsular, Bilbao, 2006. F.A. FERRER GARCÍA, El tema de la muerte en Castilla (siglos XI-XV), Memoria de Licenciatura, Salamanca, 1981.

10 J. CARO BAROJA, Las formas complejas de la vida religiosa. Religión, sociedad y carácter en la España de los siglos XVI y XVII, Madrid, 1978, p. 173.

11 K.R. SCHOLBERG, Sátira e invectiva en la España medieval, Madrid, 1971, pp. 178-179 y 371. D. ALONSO, «Pobres y ricos en los Libros de Buen Amor y Miseria de Omne», en De los siglos oscuros al de Oro, Madrid, 1958, pp. 100-108. C. GARIANO, El mundo poético de Juan Ruiz, Madrid, 1974. 
no. Por esta razón, la muerte se encuadra en la estructura global de la obra de manera decisiva, resaltando que no supone ni la liberación ni la resignación cristianas, sino la incapacidad del hombre para enfrentarse al más allá al margen de cualquier consideración teológica. Además, la percepción de la muerte se liga a la mujer, la condición externa de la fuerza sexual, la atracción física creada por la divinidad que «apenas non se pierde fasta que vien» la muerte (estr. 166d). El sentido autodestructivo de la muerte se plantea al considerarla como aniquilamiento corporal y cuando el amor se convierte en lujuria, pues el hombre «desque cumple lujuria luego se arrepiente..., acórtase la vida: quien lo dixo non miente» (estr. 274b-d). Su aceptación se mantendrá asimismo en la relación Eros-Thanatos, es decir, cuando tras el erotismo se encierra la ratificación de la vida hasta en la muerte, cuando a través del acto sexual se pone en escena la vida del ser que se reproduce, cuando tras la transgresión de la sexualidad se rompe con la monotonía cotidiana. Este es el sentido que se encuentra en el Arcipreste (también en Fernando de Rojas). El clérigo, al hablar de Venus, afirma: «Ella es nuestra vida e ella es nuestra muerte, / enflaqueçe e mata al rezio e al fuerte, / por todo el mundo tiene (muy) grant poder e suerte, / todo por su consejo se fará ado apuerte» (estr. 584).

Si la muerte es temida, también Eros, equilibrando su poder con Thanatos, provoca la lucha del hombre contra un elemento casi sobrenatural, una fuerza que no puede ser dominada por el ser mortal: «Reÿs, duques e condes e toda criatura, / vos temen e vos sirven como a vuestra fechura...» (estr. 586a-b). Sin embargo, como contrapeso, la mujer aparece como la condición de la fuerza sexual: creada por Dios como la atracción física, es exacta a las hembras de todas las especies (estr. 109-110, 1225-1227). ¿Por amor o por dinero? El amor, no obstante, para bien o para mal, está unido a la muerte, "la costumbre es otra natura, çiertamente» (estr. 166d). Y a pesar de esto, no siempre es puntualmente exacto el amor en sus límites, naciendo la frustración y el aislamiento del poeta, «nunca puedo acabar lo medio que deseo" (estr. 180c; estr. 112, 575, 577, 1316, 1317, 1393). Amor y destrucción se unen desde el instante en que el primero produce la pérdida del propio ser, la autodestrucción o la muerte (estr. 209-210, 662). El amor, cuando es lujuria, es asimismo aniquilamiento corporal, muerte:

Omne, ave o bestia a que amor retiente, desque cunple lujuria luego se arrepiente, entristeçe en punto, luego flaqueza siente, acórtase la vida: quien lo dixo non miente. ¿Quién podrié dezir quántos (la) tu lujuria mata? ¿Quién dirié tu forniçio e tu mala barata? Al que tu ençendimiento e tu locura cata, el diablo lo lieva quando non se recata.

(estr. 274-275)

Las características de las potencias del amor y la muerte son idénticas. Si una destruye a personas y almas, a los cuerpos, cambia la cordura por la locura, pierde el buen gusto el hombre, el amor tiene la naturaleza del diablo haciendo perder 
la cabeza y la palabra; la muerte, por su parte, destruye el cuerpo que ha sufrido el amor, produce dolor, tristeza, el individuo rechaza involuntariamente la palabra y el entendimiento: la vida-muerte, cuando la Muerte se presenta, disloca la dualidad belleza-fealdad. Enlazando con otras tradiciones, Fernando de Rojas contemplará al unísono la muerte y el amor, actuando ambos con idéntica arbitrariedad, una danza de amor o una danza en torno a la muerte con el trasfondo del gozo sexual al fin culminado: «Perdí mi virginidad; del cual deleitoso yerro de amor gozamos casi un mes» (XX Auto), siendo impensable la muerte en la vida, a pesar del deceso de Calisto y el posterior suicidio de Melibea desde la torre de su casa:

El color he perdido, mis sesos ya fallecen,

la fuerça non la tengo, mis ojos non parecen; si vos non me valedes, mis miembros enflaqueçen. Respondió Doña Venus: «los servidores vençen».

(estr. 607)

$\mathrm{Y}$, no obstante, todos estos procesos de enfrentamiento del Amor y la Muerte con el cuerpo humano entraban dentro de la evolución natural del hombre (estr. 943a), incluso cuando la fatalidad de la vida es movida por los deseos de venganza («el que a su enemigo non mata, si podiere, / su enemigo a él matará, si cuerdo fuere", estr. $1200 c-d$ ), cuando la muerte es una de las fuerzas dominantes de la sociedad, o cuando el hombre se siente incapaz de reconciliar su sentimiento dependiente del amor, su lazo con los demás, con la necesidad social de violentar unas normas y unos preceptos: "al que teme la muerte el panar sabe a fiel» (estr. 1379c), "con miedo de la muerte, la miel no es sabrosa» (estr. 1380c), «»todo es amargura do mortal miedo yaz» (estr. 1381d), «a morir han los onbres, que son o serán nados» (estr. 1506c).

Nada más iniciarse la lectura, una oración procedente del «Ritual de los Agonizantes", el Ordo Comendationis Animae, abre la perspectiva hacia una parodia del sermón de diviso intra, en un intento de confundir a los lectores y al público ya desde los umbrales mismos de la obra ${ }^{12}$. ¿Cuál es, entonces, el verdadero sentido de la vida en el Libro? ¿Es lo que expresa Juan Ruiz el auténtico contenido intencionado de su discurso? ¿O hay, más bien, un esoterismo que el lector ha de desenmascarar? «Fasta que el libro entiendas, d' él bien non digas nin mal, / ca tú entenderás uno e el libro dize ál» (estr. 986c-d). Si la ambivalencia se manifiesta a lo largo del poema, ¿qué decir de la intención del autor? Catecismo poético para la salvación de las almas pecadoras o catecismo para el bien amar, bien pecar, que humana cosa es y en el texto se encontrarán algunas maneras para ello, un texto, por otra parte, que se ha inspirado en todo el ciclo erótico de Ovidio y sus adaptaciones medievales, añadiendo asimismo el Pamphilus de amore, comedia popular que se remontaba a una elegía del mismo poeta latino (Amores, I, VIII) que pintaba a una alcahueta desempeñando eficientemente su oficio. Reconociendo su condición de clérigo, se somete antes a las devociones y a los deberes de la carne:

12 A. DEYERMOND, Historia de la literatura española, Barcelona, 1973, I, p. 192. 
"Que maguer somos clérigos, somos sus naturales: / servímosle muy bien, fuemos sienpre leales; / demás que sabe el rey que todos somos carnales, / quererse ha adolesçer de aquestos nuestros males» (estr. 1696).

Astros, amor y muerte constituyen en el Libro los elementos esenciales del discurso narrativo-cultural. Los tres aparecen íntimamente unidos, serán las fuerzas dominantes de toda la obra. $Y$ todo ello, a menudo, encubierto por la parodia, una de las formas más agradables y más cultas de la sátira empleada con entusiasmo por el Arcipreste. María Rosa Lida de Malkiel analiza la parodia temática como uno de los caracteres esenciales del poema ${ }^{13}$. Así, y con este elemento, la forma y el espíritu de un escritor sufren una transposición cómica aplicada a los testamentos, la misa y la liturgia, la epopeya y los procesos legales. Pero hay otros tipos, la parodia verbal y la parodia formal, en la línea apuntada por Scholberg. La parodia en Juan Ruiz es la expresión de la vida festiva de ese gran cuerpo popular, un lenguaje en parte carnavalesco que se alejará claramente al utilizado por otros escritores como Don Juan Manuel o López de Ayala, aunque también en estos últimos existen degradaciones paródicas. La estructura fluida y compleja del Libro, la desconcertante transición entre ficción y realidad, la propia autobiografía erótica, la exuberancia y variedad de la métrica (rasgos todos ellos resaltados a menudo por Américo Castro y puestos en relación con El Collar de la Paloma) son características de un mundo mucho más complejo. Mundo en el que, aparte de las posibles relaciones con la literatura hispano-arábiga, lo popular adquiere un relieve definido. Pero, esta obra ¿es simplemente una parodia?, ¿o es una parodia de toda una corriente literaria, cultural e ideológica de los grandes temas que inquietaban al hombre medieval, el sufrimiento y la muerte? Decididamente, Juan Ruiz y su obra tienen unas dimensiones más amplias de las que a veces se han señalado: la ironía y la ambivalencia del Libro son rasgos que le confieren grandes dimensiones dentro de la corriente de una literatura popular, pues no sólo algunas estrofas sino toda la obra es una parodia del didactismo medieval ${ }^{14}$.

El tema de la muerte en el Libro de Buen Amor tiene un sentido muy específi$\mathrm{co}$, siendo la obra cumbre de las letras castellanas desde esta perspectiva. «Contra el propósito moralizante -escribe Rafael Lapesa- impuesto a Juan Ruiz por el didactismo en que se formó y vive, se conjuran dos cosas: el espanto que produce la idea de la muerte y la necesidad vital de olvidarse de ella»15. Así pues, en el arcipreste castellano se conjugan varios temas e ideas: el carácter expansivo de la muerte, su carácter antropofágico relacionado con los cultos a una Dea Mater, el tema del juego, la figura de la mujer, la muerte como hecho real y material, como hecho omnipotente y escasamente comprensible, Satán, el alma y el infierno, la reencarnación y el renacimiento. Se ha señalado en varios estudios que el Arcipreste

${ }_{13}$ M. ${ }^{\text {a }}$ R. LIDA DE MALKIEL, «El estilo de Juan Ruiz y la construcción del episodio de doña Garoza», en F. RICO y A. DEYERMOND (eds.), Historia y crítica de la literatura española. I Edad Media, BarceIona, 1979, pp. 239-246.

14 K.R. SCHOELBERG, op. cit., pp. 178-9.

15 R. LAPESA, «El tema de la muerte en el Libro de Buen Amor», en De la Edad Media a nuestros dias, Madrid, 1967, p. 56. 
de Hita no era consciente de su propia muerte, sino que la conocía por su propio entorno, especialmente por una canalización por medio del amor físico, concentrándose en sus versos tanto un ánimo desolado por el fallecimiento de la Trotaconventos como por la ausencia de la servidumbre profesional de la vieja alcahueta. Juan Ruiz «no piensa en la muerte como una liberación de los males terrenales y de la supuesta cárcel de este mundo a la que erróneamente algunos comentaristas suponen aludiendo. Nunca habría escrito como Teresa de Ávila: 'que muero porque no muero', o como Luis de León: '¿Cuándo será que pueda, / libre de esta prisión / volar al cielo?'... La muerte desmesurada le inquietaba cara a la rendición de cuentas, y es la confesión de los pecados el único tema del cual no se atrevió a burlarse ${ }^{16}$.

En definitiva, la muerte adquiere su máxima personalidad en el treno a la Trotaconventos («De cómo morió Trotaconventos e de cómo el Arcipreste faze su planto desnostando e maldiziendo la muerte», estr. 1520-1575) ${ }^{17}$. Una primera lectura de las anteriores estrofas sugiere efectivamente que Juan Ruiz no piensa en el carácter redentor de la muerte. En este sentido se aleja de la ortodoxia cristiana, pues al no suponer ni liberación ni resignación es difícil establecer una reconciliación entre su posición como clérigo y lo que se ha denominado «gran problema existencial» del de Hita. El planto que el Arcipreste hace a la Trotaconventos constituye, en la línea de la obra, una degradación paródica de la muerte y de un texto religioso. La vanidad de la vida no existe en el «buen amor», pues tampoco puede hablarse de la fragilidad de la vital aislando y manipulando el texto literario. Por esta razón, al separar de la temática central la estrofa 105, en la que el poeta escribe "que las cosas del mundo todas son vanidad, / todas son pasaderas, vanse con la edad, / salvo amor de Dios, todas son liviandad", se observa que en cierto sentido no ofrece conflicto alguno, pero al retrasar la lectura se tropieza el lector con el lamento de Juan Ruiz por el plantón que le ha dado una mujer conocida poco antes (estr. 71-81: «De cómo el Arçipreste fue enamorado»). El afán democratizador de la muerte (que aparecerá nítidamente en las «Danzas de la Muerte») apenas se percibe, exceptuando unos versos en los que el poeta alude a la igualdad social tras la muerte: «Muerte, al que tú fieres, liévaslo de belmez, / al bueno e al malo, al noble e al refez, / a todos los egualas e lievas por un prez, / por papas e por reyes non das una vil nuez» (estr. 1521).

Se destrozan los propósitos moralizantes y didácticos de la Edad Media, se acentúa incluso una imagen festiva basada en el propio cuerpo, sus dones (lozanía, juego, gracia, etc.) son derribados por la «enemiga del mal e del mal amador», atenuada por la risa del clérigo por un planto burlesco plagado de hilaridad. El carácter expansivo de la muerte, su antropofagia, su juego y relación con el último aliento de vida y el despojo de los bienes para el difunto son cualidades que cobran fuerza en el treno: « $\mathrm{A}$ todo!: / viene un mal azar, trae dados en rodo; / llega el

16 C. SÁNCHEZ-ALBORNOZ, España, un enigma histórico, Barcelona, 1977, I, p. 449.

17 J. RUIZ, ARCIPRESTE DE HITA, Libro de Buen Amor, J. Joset ed., Madrid, Espasa-Calpe, 1974; A. Blecua ed., Madrid, Cátedra, 1995. 
omne thesoros por lograrlos, apodo; / viene la muerte luego e déxalo con lodo» (estr. 1534). Comprensible por la fecundidad, la muerte adquiere su sentido en el papel de la alcahueta, que por ser vieja «es inmensamente joven: por la bipolaridad de la energía psíquica, en el fondo del inconsciente cada cosa es idéntica a su contraria, es decir, por ser vieja, por tener la vejez de la Luna, la Trotaconventos es la condición de posibilidad de todo amor joven »18. La muerte así constituye el eje de la vida y obra de Juan Ruiz, junto a las potencias del amor y los astros. Al lado de los elementos más tradicionales de la Edad Media como las lamentaciones, panegíricos, el Ubi sunt?, aparece también el elemento renovador de la compensación de la muerte por Jesucristo, un héroe cosmogónico. Pero tampoco se sabe qué es una buena muerte para el arcipreste. Y, ¿para otros vecinos castellanos?

\section{LA PERCEPCIÓN DE LA MUERTE. EL ALMA Y EL MÁS ALLÁ}

A diferencia de los santos, el hombre medieval de los siglos XII, XIII y buena parte del XIV no tenía conciencia de su propio fin, no deseaba la muerte, ni se alegraba, ni siquiera reflexionaba sobre el último instante. Excepcionalmente, Jorge Manrique, ya a mediados del siglo XV, planteará una muerte diversificada y asumida en un alarde de virtuosismo y conceptismo retórico: «No tardes, Muerte, que muero; / ven, porque viva contigo; / quiéreme, pues que te quiero, que con tu venida espero / no tener guerra conmigo", Canción, vv. 1-5). Un caso aislado.

El hombre enferma y los familiares se interrogan a sí mismos y a otros «quando por su dolençia al físico preguntan» (estr. 1538c), iniciándose así la presencia social de la muerte por medio de la agonía del enfermo, rodeado de una familia que prontamente tratará sobre la herencia, reclamará en el momento del óbito el toque de campanas, aguantará en el velatorio, organizará las exequias y otros actos litúrgicos (oraciones, sacrificios, oficios), encargará sufragios y celebrará, dentro de la tradición popular, la comida de difuntos. Inmediatamente se perciben las consecuencias físicas del fallecimiento. «La salud e la vida muy aína se muda: / en un punto se pierde, quando omne non cuda» (estr. 1531a-b).

Para los agoreros, la muerte se acercaba a la casa por medio de un búho, un cuervo, un ave de rapiña. El cuervo, por ejemplo, es su mensajero por la negritud, la rapacería y su ansia carnívora, liquidando la vida por su propio carácter antropofágico, deseoso del cadáver al contrario que los hombres que procuran apartarse de la muerte, "salvo el cuervo negro, que de ti, muerte, s' farta" (estr. 1529d). "Señores, non querades ser amigos del cuervo, / temed sus amenazas, non fagades su ruego" (estr. 1531a-b). Como recurso literario, la presencia del cuervo se hará notar en algunas obras. En el romance «La Muerte Ocultada», pro-

18 W. ROSS, «Nota sobre el sentido de la muerte en el Libro de Buen Amor», en AA.VV., El Arcipreste de Hita. Actas del I Congreso Internacional sobre el Arcipreste de Hita, Barcelona, 1973, p. 108. 
cedente del siglo XV y recogido por Menéndez Pidal ${ }^{19}$, todo un itinerario anuncia la presencia de la muerte: siete leguas sin encontrar cosa viva, cuervos negros, una encina seca, nieve y agua fría conducen al enfrentamiento con la vida que, no obstante, se alarga por una renovación-fecundidad llena de ambivalencias. El cuerpo que muere es el fecundante, mientras que el fecundado da una nueva vida, «la muerte preñada". En este mismo sentido, en numerosas obras literarias, especialmente en los romances populares, la muerte está unida al nacimiento: «A eso de la medianoche / la casa se estremecía: / en el cuarto de don Pedro / grandes lamentos se hacían; / en el cuarto de doña Alda, / al niño hacen alegrías» (vv. 3540). Así, la imagen de la vida unida a la renovación descalificaba el matiz trágico de la muerte. La degradación paródica se da asimismo ante los hechos vitales de transición (nacimiento y matrimonio), siendo la asociación muerte-risa una característica de las carnestolendas, las fiestas populares, las «diabladas» y la degustación de las almas pecadoras, "ca la vida es juego». El «morir de risa» se convertía en una de las variantes de la muerte festiva ${ }^{20}$. Por otra parte, habrá que recordar el propio carácter antropofágico de la muerte, que se devora a sí misma para volver a surgir, circunstancia relacionada con los cultos ancestrales a la Dea Mater.

Similares planteamientos se aprecian en los romances de los siglos XV y XVI, a pesar de la dificultad de establecer una cronología precisa debido a la tradición oral, el dramatismo y cierto carácter épico, tal y como apuntaba Ramón Menéndez Pidal. La aceptación de la idea de la fama, un ideal caballeresco, se une al desconocimiento de cualquier consolación de tipo ultraterreno-religioso, aspecto que Camacho Guizado atribuye a la confluencia de la moral nobiliaria y al apogeo de las ideas renacentistas en torno a la fama como trascendencia de la muerte ${ }^{21}$. En «Amor más poderoso que la muerte», romance del siglo XV contaminado por las versiones sobre el infante Arnaldos, la muerte es representada alegóricamente, como un acto que viene a cortar la vida de dos amantes pese a la advertencia regia de imposibilitar los goces que se suponen carnales. La muerte está en la medianoche, en la de san Juan, un momento propicio para desacralizar y paganizar la vida. El agua y la sirenita vienen a ser dos elementos importantes, pues comunican a la princesa y al conde a la vez que establecen una relación amor-muerte entre ambos. La muerte de un amante por la ausencia del otro es un tema que se repite constantemente en Juan Ruiz (estr. 584, 791, etc.) o en Ibn Hazm (El collar de la paloma, XXVIII).

El romance «El enamorado y la Muerte» procede de uno de Juan del Enzina que comienza «Yo me estando reposando, durmiendo como solía...». Posee una simbología propia, pues la Muerte es identificada con la noche negra, pero también con la noche de sueño y amor. Imagen real, la Muerte se personifica por su inme-

19 R. MENÉNDEZ PIDAL, Flor nueva de romances viejos, Madrid, 1980, pp. 213-216. «La Muerte Ocultada", romance del siglo XV en versión de finales del XVII.

20 M. BAJTIN, La cultura popular en la Edad Media y en el Renacimiento. El contexto de François Rabelais, Barcelona, 1974, p. 367.

${ }^{21}$ E. CAMACHO GUIZADO, La elegía funeral en la poesía española, Madrid, 1969, p. 119. 
diata blancura y palidez, por la forma cadavérica que, al mismo tiempo, se identifica con la blancura y pureza del amor. Su aparición súbita, repentina, provoca en el amador la confusión entre la Muerte y el Amor. Es «pronta», rigurosa en su llegada. El dramatismo se centra al contraponer la llegada de la muerte con la búsqueda amorosa: a su lado, la muerte vida sería. Por otra parte, el encuentro de los enamorados y la Muerte recuerda el accidente y fallecimiento de Calisto. La presencia de la Muerte interrumpe la vida, el amor y el sueño. El segundo salva a la Muerte, o tendría que salvar a la vida, pero no es así, al menos no salva la vida de este mundo dado que ha sido enviada por la divinidad cortando el cordón de seda que une a los dos enamorados.

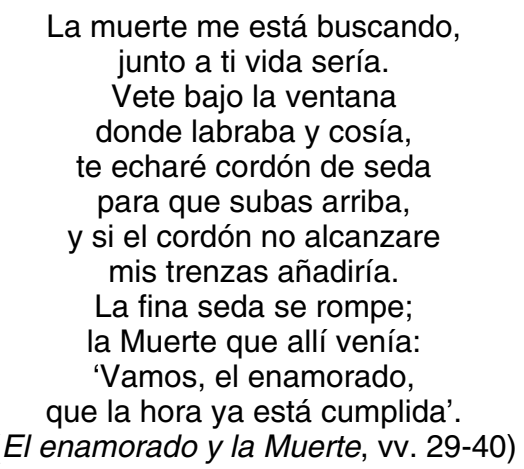

«... Et tanto era el mal que se facía en la tierra que aunque fallasen los omes muertos por los caminos non lo avían por extraño...» (Crónica del rey don Alfonso el Onceno, XXXVII). Acostumbrado a contemplar al muerto ajeno, el hombre castellano sentía sin embargo un profundo rechazo al cadáver cercano. El cuerpo del hombre muerto sometía a la mente humana a un miedo inspirado por el propio cadáver y sus alteraciones anatómicas, el crecimiento incomprensible del cabello, la putrefacción de la carne, la decadencia física bajo formas más o menos macabras en la literatura. El ermitaño, un hombre bueno que casi desconoce el mal, cuando rezaba una noche tiene una revelación acerca de un cadáver: «Topé con un omne que yacía finado: / holía muy mal, ca estaua fynchado, / los ojos quebrados, la fas denegrida, / la barba abierta, la barba cayda, / de gusanos e moscas muy acompañado" (Reuelaçión de vn ermitaño, vv. 12-16) ${ }^{22}$.

La descripción es directa y hasta cierto punto tosca. El elemento de la caducidad de la vida está identificado con el cuerpo, mientras que el alma representa la no-muerte, siempre y cuando se haya vivido bajo los preceptos eclesiásticos. El horror a la muerte se manifestaba en la negación, en el cuerpo corrompido, de la belleza y la dicha: en el valle donde se encuentra el cadáver el eremita choca con dolores y tormentos. El autor, anónimo, no se detiene ante el simple hecho de la

22 «Revelación de un ermitaño», en J. SAUGNIEUX, Les Danses macabres de France et d'Espagne et leurs prolongements littéraires, Lyon, 1972, pp. 245-250. 
muerte, sino que se introduce en un terreno de lo macabro que desconoce radicalmente cualquier tono elegíaco tan característico de algunos plantos. El aspecto más grosero es el que mejor penetraba en la mentalidad del hombre medieval. Y este horror ante la descomposición del cadáver explica el valor atribuido a la incorruptibilidad del cuerpo santo, que será uno de los componentes fundamentales del culto de las reliquias.

Las descripciones continuarán también durante el siglo XV. Papas y príncipes, como pobres y campesinos, no pueden remediar la descomposición. Vita mutantur, non tollitur. la vida no fenece, se transforma, pero el cuerpo muere y se pudre. La muerte del papa Pablo II, en 1461, no es una muerte ejemplar precisamente: la resurrección del cuerpo en el Juicio Final hará que el alma se una a una materia que en ningún caso se asemejaba al cuerpo que en vida tuvo el pontífice, «el qual, como fuese muy hermoso de gesto, e de cuerpo muy grande e muy sano, sin enfermedad alguna, la noche que murió fue fallado en su cama tan pequeño e tan flaco como de un mozo pequeño de diez o doce años, todo consumido e ferido el rostro e la cabeza en muchos lugares, e los huesos de tal manera como si fuesen quemados en fuego. (...) E muerto así el Padre Santo, los suyos dieron muy gran priesa a su enterramiento, porque no fuese todos manifiesta la nueva forma de su muerte, la qual bien conforme fue a su vida, como siempre se diese a deleites e pompas e otras vanas dejando entender en las cosas a que su divinidad le obligaba. (...) Fue enterrado miserablemente en una pobre sepultura...» (Diego de Valera, Memorial de diversas hazañas, LXIII).

Para la segunda mitad del siglo XV, Alberto Tenenti señala que en un tiempo en que predomina una «religión de la muerte» 23 , el moribundo no es considerado como un cuerpo próximo a la descomposición, ni como un organismo sufriente, pues el dolor físico no encuentra su papel en la literatura, no juega ningún papel, ya que la extinción de la vida orgánica era un acontecimiento natural nacido de un gasto, una erosión del cuerpo anunciada desde el nacimiento. El drama tenía lugar en otro plano, pues ya el moribundo no era más que su alma. ¿Hasta qué punto esta actitud era característica del mundo medieval en el siglo XV, concretamente en Castilla y más ampliamente en la Europa occidental? La visión de los últimos momentos, los Quattuor hominum novísima, aunque no era discutida en la comunidad cristiana, dio paso tanto en los grupos cultivados como en las clases populares a la contemplación de la muerte como una realidad más estrictamente humana y terrenal. La potencia y el triunfo de la muerte era, primero, la decadencia física, luego el juicio particular, la elección del destino entre el cielo y el infierno. Una temática ciertamente macabra se iba incorporando a la literatura cuando se escribía sobre todo aquello que participa de la fealdad de la muerte y la repulsión que ésta suele causar. El movimiento comenzó a partir del siglo XIII como una alteración de la vulgata de la muerte mantenida por el cristianismo. Y el punto más

${ }^{23}$ A. TENENTI, "Ars moriendi. Quelques notes sur le problème de la mort à la fin du XV siècle», Annales E.S.C., V (1951), p. 437 (433-446). 
alto se dará a finales del siglo XV y primeros años del XVI con la proliferación de las «Danzas de la Muerte».

Lentamente el hombre asistía a su propia muerte, reflejada en la del moribundo cercano, descubriendo el speculum mortis, planteándose entonces «racionalmente" la muerte de sí mismo. Frente a la familiaridad y resignación en la muerte en los siglos XI, XII y parte del XIII, el sentimiento de la muerte individualizada se agrega al anterior desde el momento en que el hombre toma conciencia de su fin próximo, la descomposición corporal y la salvación o condena del alma. El aislamiento del cuerpo putrefacto revela la presencia opresiva de la muerte, describiéndose a veces meticulosamente sus consecuencias en el caso de don Carlos, duque de Guiana y hermano del rey francés san Luis: "súbitamente vio tal enfermedad que se le cayeron las barbas e cabellos e cejas, e las uñas se le apartaban de la carne, con gran dolor, e otras muchas señales parescieron en él» (D. de Valera, Memorial..., LXXV). En otros casos, tanto la enfermedad como la muerte es achacada por el actor histórico que las sufre a fuerzas exteriores y ajenas a su condición física (Dios, los judíos, etc.). El mal es un castigo, una prueba o una venganza, y el cristiano debe buscar en sí mismo el remedio bien a través de la práctica médica, el aislamiento del cuerpo enfermo, bien gracias al arrepentimiento final, la oración, el acantonamiento o el pogrom. Pero, antes del siglo XIII, la muerte del hombre, especialmente si es un rey, era considerada como un acontecimiento natural en el que, a pesar de las dudas, no había intervenido mano humana. «... Et el rey don Sancho, non se percibiendo de tal trayción nin se guardando della, mordió en la mançana et sopol bien et comiola, et luego que ouo comida sintiose mal de muerte, et entendió que aquel tan grand mal que de muert era. Et mandose luego leuar pora tierra de León; et se leuandol por allá muriose en la carrera a cabo de tres días. Et ninguno de los suyos otrossí non ouo y quien entendiese que aquella muerte non era natural nin que de yeruas fuesse nin de otra poçón, mas que muerte natural fuera que uniera al rey don Sancho como viene a los reys et a los otros omnes, et que muriera de aquella guisa» (Primera Crónica General, 723).

Frente a la muerte inexplicada, frente a las sospechas prohibidas y mantenidas, quedaba el cuerpo del hombre como signo fatal de una muerte que, en aras del más allá, le dejaría convertido en polvo, «yermo a gusanos e fuesa» (estr. 1524a). La muerte, además, estimula el cambio de los dones físicos y mentales:

Tiras toda vergüenza, desfeas hermosura,
desadonas la graçia, denuestas la mesura,
enflaqueçes la fuerça, enloqueçes cordura,
lo dulçe fazes fiel con tu mucha amargura.
Despreçias lozanía, el oro escureçes,
desfazes la fechura, alegría entristeces:
Muerte, matas la vida, et amor aborreces.

(estr. 1548-1549) 
La muerte no es solo un castigo. También el fallecimiento y el cadáver delatan al pecador o al asesino. Y la muerte acarrea el propio castigo para el culpable: «e ella fue colgada; que fue juizio de Dios donde ella oviera de aver toda la culpa de la muerte de su padre. E Dios quería que aun ella biviese e ficiese penitencia, e ella non quiso e así acabó. E aún después de muerta fue cabsa de la deshonra del verdugo: que ay personas que en vida e en muerte siempre fazen el mal o son causa de todo mal, que en tal signo nacieron" (A. Martínez de Toledo, Arcipreste de Talavera o Corbacho, $1^{a}$ parte, c. XXIV, M. Gerli ed.). La «Voz de la sangre», el olor nauseabundo y el grado de putrefacción del cadáver señalan el comportamiento en la vida. Peccator plus fecit quam cadaver. «Porque este doncel hermoso, por el fedor de los pecados, más fiede delante de Dios e de los ángeles que el cuerpo muerto de aquel que tú non podías sofrir el fedor» (C. Sánchez de Vercial, Libro de los enxemplos por A.B.C., 352-291, J. Alcina Franch ed.).

Seres aparentemente excepcionales, los santos en la Edad Media tiene conciencia de su propio fin, reciben con alegría la muerte, la desean y reflexionan. La soledad de estos personajes se rompe con los monjes o con los violentos en el caso de los mártires. La divinidad aparece tras la propia muerte. Cuando Dios se muestra lo hace tan solo como visión, sin contacto directo con el moribundo: «quando acabó su oración, / vio una buena visión: / buenos mandaderos vayo yo aquí. / Mi cuerpo e my alma acomjendo a ti» (Vida de Santa María Egipciaca, vv. 1322-1325, M.S. de Andrés Castellanos ed.). Reposar en tierra, cerrar los ojos, la boca, envolver los cabellos, las manos sobre el pecho: el alma sale del cuerpo, los ángeles la reciben y el diablo no la atrapa. El infierno queda lejos, pues la santidad del personaje calma las inquietudes.

Para el resto de los hombres, muerte y alma tienen entre sí una relación que suele aparecer normalmente en la literatura a través de diálogos, disputas o enfrentamientos. El más allá está asimismo reflejado en las obras artísticas y literarias. Desde la Alta Edad Media se suceden en la Península las reflexiones sobre el trasmundo: Pablo, diácono de Mérida, dedica su primer capítulo de las Vitae Sanctorum Patrum Emeritensium a este tema, al igual que Valerio del Bierzo en De uana saeculi sapientia, en De maximo Monaco qui Valerio uisionem propriam retulit de Paradisi amoenitate et de lamentu baratri, De bonello Monaco cui reuelatio inferni facta est y De caelesti reuelatione facta Baldario ${ }^{24}$. Luego, en el Mester de Clerecía, el otro mundo es representado como un lugar a orillas de un río, "oriella de un flumen tan fiero como el mar» (estr. 229b), dice Berceo en su relato sobre santo Domingo. Son dos ríos los que atraviesa el hombre, uno rojo y otro blanco. El paraíso es el triunfo que con la ayuda indispensable de Dios se alcanza: «Por este sieglo pobre, que poco durará, / non perdamos el otro mundo que nunca finará, / mezquindad por riqueza, ¿quí no la cambiará? / Qui buscarla quisiere rehez la trobará» (estr. 246).

24 Vid. H. FLÓREZ, España Sagrada. Teatro geográphico-histórico de la Iglesia de España, Madrid, Antonio Marín, 1758, T. XVI, pp. 377, 380 ss. 
En el Libro de Alexandre el otro mundo está presente. También en el Libro de miseria de omne se desarrolla una amplia descripción de las torturas infernales. Más tarde, don Juan Manuel concibe el otro mundo como una isla: al hombre «desnuyábanle e echávanle en una isla solo, que no fincaba con él omne del mundo» (El Conde Lucanor, Exemplo XLIX). El valle es otro motivo expresivo del trasmundo: «En vn balle fondo, escuro, apartado, / espeso de xaras somné que andaua / buscando salida e non la fallaua» (Reuelaçión de un ermitaño). El más allá, en definitiva, es un tema que en la literatura medieval presenta dos situaciones, el paraíso o la montaña, río, puente, jardín; el infierno o el valle profundo y oscuro, el territorio pantanoso. El infierno, escribía Juan Ruiz, es la habitación de la muerte: «Tu morada por siempre es infierno profundo, / tú eres el mal primero e él es el segundo, / pueblas mala morada e despueblas el mundo, / dizes a cada uno: 'Yo sola a todo hundo'. / Muerte, por ti es fecho el lugar infernal, / ca, beviendo omne siempre en mundo terrenal, / non avrié de ti miedo nin de tu mal hostal, / non temerié tu venida la carne umanal» (estr. 1552-1553).

La esencia primaria de la muerte en el mundo medieval es la separación del alma y cuerpo, en ocasiones la conversación que mantienen tras la llegada de la muerte. El cuerpo queda desamparado, pues tras vivir sometido al alma, ésta le abandona, surgiendo las disputas. En la Disputa del alma y el cuerpo (vv. 1-37) el alma está ya fuera del cuerpo, «desnuda ca non vestida». Representación del mal, el cuerpo es acusado de la desgracia del alma, pues ni hizo bien ni fue al altar, ni siquiera ofrendas quería dar, «ni diezmo ni primicia ni buena penitencia; ni fecist oración nunca de corazón», a «apóstol ni mártir quisist seruir». La fugacidad de la vida, la vanidad de los bienes surge en la disputa cuando el alma acusa: «o son... las copas d'oro fino con que beuies to uino? / Do son tos bestimentos?, ¿o los tos guarnimientos?». Numerosas implicaciones presenta la muerte. Siempre se deduce el sentimiento del hombre medieval ante la muerte y su condición inexorable.

Ninguno non se puede escusar de la muerte, por maña nin por arte, nin por ninguna suerte; non prestan melezinas, nin otra cosa fuerte, nin trapos a los pies, nin bizmas a la fruente.

(Proverbios en rimo del sabio Salomón, rey de Israel, vv. 23-27)

Devemos estar çiertos, non seguros, de muerte, ca nuestra enemiga es natural e fuerte; non podemos, amigos, d'ella füir por suerte, por ende cada uno de nos sus armas puerte.

(Libro de Buen Amor, estr. 1580)

\section{LOS RITUALES FUNERARIOS Y EL RECUERDO DEL DIFUNTO}

Desde que barruntaron la muerte del familiar, los parientes vivieron pendientes de un hilo por el conocimiento de las cláusulas testamentarias. Así pues, asumida 
la condición inexorable de la muerte por los vecinos castellanos, hasta que se llega a la gloria o al infierno transcurren unos ritos, unas costumbres y formalidades que se regulaban por medio de las disposiciones legales de la Edad Media. Ya desde la extensión y consolidación jurídica de los fueros municipales se insistía en el fuerte tinte material, en el carácter pecuniario que adquiría el óbito, regulándose en diferentes títulos desde la propia muerte del hombre, vecino o morador, pasando por el deceso de la mujer, del judío, moro, etc., o el homicidio, concretándose incluso la forma de los funerales, las prácticas testamentarias o sus regulaciones en caso contrario, cuestiones en torno a los hijos huérfanos y, especialmente, acerca de las viudas. Destacaba el papel social de la enfermedad en el mundo medieval, de modo que los vínculos de sangre, las relaciones familiares, vecinales y económicas se hacían presentes, sobre todo, con el desarrollo del viático La presencia de una enfermedad terminal provocaba la aparición de algunos rituales solidarios, o no tanto, cuando el moribundo "pierde luego la fabla e el entendimiento", "dexánlo en tierra solo, todos han d'él pavor» (estr. 1535a/ 1538b). Instantes antes ha recibido el viático, anunciado en la ciudad, villa o aldea por un toque de campanas que unía a los vecinos en una especie de procesión, término éste, "viático", tardío y relacionado con los cultos mistéricos. A veces, el moribundo era consolado por alguna cofradía de ánimas, estableciéndose ya desde las Cortes de 1268 su papel «non para otros paramentos malos», sino «para dar a comer a pobres o para luminar o para soterrar muertos...» (1.41). La agonía parecía ser, para bien o para mal, el instante esencial, notificada con tres toques de campanas, el "encordar», acompañada de rezos (al igual que en el velatorio) cuando se distribuían los vecinos en dos grupos, las mujeres y los hombres, unas rezando en la habitación del cadáver, otros en la cocina, en una representación parcial de la muerte festiva desde el instante en que tiene lugar una comida que, en ocasiones («entiéranlo de grado e, desque a graçias van»), se repite tras el entierro. Huizinga señaló para la Edad Media que «la imagen de la agonía era la primera de las cuatro postrimerías, de los Quattor hominum novissima, sobre los cuales debía el hombre meditar continuamente: muerte, juicio, infierno y gloria»25. El toque de ánimas, realizado a lo largo de todo el año, al atardecer, marcaba la vida cotidiana del pueblo. Unos versos latinos recogidos en el siglo XVIII por el sacerdote José Tello Martínez señalaban los efectos que las campanas tenían en las sociedades preindustriales: Sex in campana dicuntur commode sana: / laudo Deum verum, voco populum, congrego clero, / defunctos ploro, Sathanam fugo, festa decoro.

En ese fugaz y agónico momento, el moribundo, temeroso de la muerte, enfermo de cuerpo pero normalmente sano de espíritu, buscaba el arrepentimiento, perdonaba a sus deudos y vecinos, buscaba el consuelo del clérigo esperando, de acuerdo con las normas eclesiásticas, un retorno a Dios, la reconciliación en la otra vida, mientras que la mala muerte equivalía solamente a la interrupción de la vida, un momento cualquiera de su curso. Las plañideras, en el velatorio, desem-

25 J. HUIZINGA, El otoño de la Edad Media, Madrid, 1930, I, p. 211. 
peñaban eficazmente su labor, al igual que las rezadoras. «Había que manifestar públicamente este dolor y duelo femenino ante la opinión pública, por eso se contrataban otras mujeres para hacerlo ${ }^{26}$. La sociabilidad envolvía al moribundo en sus últimos momentos, al cadáver cuando el aniquilamiento corporal tenía que dar paso, según los cánones, a la futura salvación. Y surgía una actitud especialmente femenina en la casa fúnebre, sobre todo con los lamentos verbales y físicos, mientras que, para los hombres, se iniciaba la ardua tarea de masculinizar el fallecimiento (o la viudez del esposo) atendiendo especialmente al rango individual del cadáver. Dependiendo de sus cualidades sociales y económicas, de los dineros invertidos por la familia y de las relaciones con la comunidad, la persona muerta era llorada y alabada, manifestándose así la veneración cristiana por los muertos justificada por la esperanza de la resurrección de los cuerpos. Desde los antiguos tiempos, los cristianos consumían más aromas e inciensos para honrar a los muertos que los paganos para adorar a sus dioses, afirmaba el rigorista Tertuliano. En las obras artísticas se reflejará este modelo de defunción y ritual de paso cuando se representan los grupos funerarios, como en las «Tablas de la tumba de don Sancho Sainz Carrillo» (MNAC, Barcelona), procedentes de Mahamud (Burgos) y realizadas hacia el año 1300, observándose los elementos heráldicos y un séquito de llorantes y plañideras organizado en cuatro registros. "Manda que ningún cavallero non llanga nin se rasque sinon fuere por señor, e que ninguno non traya pannos de duelo por otro sinon fuere un par, sinon por señor o mugier por su marido que lo traya quanto quisiere» (Cortes de León y Castilla, 1258, 1.25). Llantos desordenados que estaban avalados por una tradición eclesiástica y litúrgica, pero siempre dentro del terreno de la privacidad y con cierta mesura, prohibiéndose "que ningún ome nin muger non faga duelo públicamente rascándose nin mesándose nin quebrantado escudos» $(1379,1.4)$, pues en caso contrario parecería que los parientes y amigos del finado "dan a entender que no les plaze lo que Dios faze, e que se desesperan de la vida perdurable. E segund la Santa Escriptura los que finan non muestran otra deferencia sobre sy como aquellos que pasan de un lugar a otro, e los que bien fazen en esta murida averán después de Dios galardón» (Cortes de León y Castilla, 1380, 1.4).

Se lamentaban los deudos ante la llegada lenta o precipitada de la muerte. Sin embargo, en la literatura anterior al siglo XIV no existía el dolor, el lamento o la desolación ante la propia muerte en santidad, mientras que desde el siglo XI el planctus relacionado con los grupos dirigentes de la sociedad exaltaba precisamente el dolor ante la pérdida humana. A pesar de esto, tanto en los textos castellanos como en un buen número de monumentos funerarios la reacción ante la muerte del otro es bastante limitada, inscribiéndose en lo que Ariès denominó «Tamed Death ${ }^{27}$, una muerte domesticada, sometida o reducida al ámbito familiar. O una «muerte vencida» anterior al año 1300, en expresión de Emilio Mitre. Como la

${ }^{26}$ M. SÁNCHEZ, Vida popular en Castilla y León a través del arte (Edad Media), Valladolid, 1982, pp. 121-123.

$27 \mathrm{PH}$. ARIÈS, Western attitudes.... Trad. española: El hombre ante la muerte, Madrid, 1983, pp. 1320. Vid. PH. ARIĖS, La muerte en Occidente, Barcelona, 1982. 
muerte del santo, la del héroe apunta a la conciencia que tiene de su propio fin, una fatalidad escasamente dramatizada en la que se trata de recordar la juventud del finado o el efecto propagandístico de sus virtudes. Un lamento podía surgir en la desolación tímida y la soledad acentuada en la que quedaban los familiares y amigos, Carlomagno y Gonzalo Gustios cuando, respectivamente, perdieron a Roldán (Cantar de Roncesvalles, vv. 8-16 y 29-33) y a sus hijos (Cantar de los Infantes de Lara, vv. 26-30 y 97-100). Las reacciones de dolor son escasas en la literatura mortuoria. Howard Rollin $\mathrm{Patch}^{28}$ puso de manifiesto la repetición de ciertos esquemas, símbolos, ritos y situaciones a lo largo de la historia funeraria, al mismo tiempo que subrayaba la lenta evolución de unas formas de muerte caracterizadas por el duelo controlado o domado y la transición a un más allá. Por otra parte, el deceso del santo, natural o violento, deja el rastro de una fama, una actitud ante la vida que es capaz de suministrar cierto consuelo a los fieles. Como muerto, el santo se convertirá en un medio accesible para el más allá y de cara a la divinidad. Al igual que el héroe, el mérito del santo difunto se dirige a resaltar sus virtudes y características nobles, un precedente de la fama laica que resurgirá con fuerza en los últimos siglos de la Edad Media. Así pues, el fallecimiento del santo se caracterizaba, sobre todo, por su aceptación, el presentimiento y la virtus del muerto, «la energía que se manifiesta a través de su cuerpo» ${ }^{29}$, aunque esté mutilado por los tormentos y aparezca para el resto de los humanos en un cenotafio íntegro e ileso.

Además, su muerte olvida a los vivos, les aleja de cualquier duelo al uso civil como desgarros, lamentos, pruebas físicas del dolor, mesado de barbas, acompañamiento de plañideras. La solitaria muerte de algunos santos contrasta evidentemente con los fallecimientos literarios de Roldán, los infantes de Lara o Patroclo en la Historia Troyana (I, vv. 21-27), pues en los tres casos se reproducen lamentos y preguntas hacia los muertos. Tanto Carlomagno como Gonzalo Gustios, lo mismo que luego Jorge Manrique y otros autores, interrogan a los seres perdidos, se plantean «interrogaciones no interrogantes» ${ }^{30}$, es decir, que no esperan respuestas concretas o que poseen una respuesta tan clara que ya la interrogación es una protesta evidente. «Entonces podrá preguntar, Muerte, dónde está tu victoria, sabiendo no obstante que no recibirá respuesta, porque la muerte nunca responde, y no es porque no quiera, es sólo porque no sabe lo que ha de decir delante del mayor dolor humano" (J. Saramago: Las intermitencias de la muerte, 2005). Las preguntas lamentadas se dirigen a una muerte abstracta, aunque inmediata, pues el muerto «nada sabe y ya no espera recompensa, habiéndose perdido ya su memoria» (Eccl. 9, 5). Y, por otra parte, se va recomponiendo un ideal caballeresco acerca de la muerte misma desde el momento en que se insiste en un elogio superlativo, en una propaganda exagerada sobre las cualidades

${ }^{28}$ H.R. PATCH, El otro mundo en la literatura medieval, México, 1956. Vid. M. ${ }^{a}$ R. LIDA DE MALKIEL, «La visión del trasmundo en las literaturas hispánicas», apéndice en H.R. Patch, pp. 369-449.

29 A. VAUCHEZ, La saintité en Occidente aux derniers siècles du Moyen Âge d'après les procès de canonisation et les documents hagiographiques, Rome, 1988, p. 499.

30 E. CAMACHO GUIZADO, La elegía funeral..., p. 61. 
del difunto. Los milagros de los santos tras la muerte, sobre su propia tumba, por el contacto con una reliquia o, simplemente, por su recuerdo mediante la oración, vendrían a ser el equivalente de la fama del caballero que pretende dejar a los vivos su fortuna, la honra sostenida y el mantenimiento de un linaje. Así, el caballero actúa mientras vive pensando más bien en un tipo de coerción que, mediante la oración y otros medios materiales (donaciones pro anima, por ejemplo, o el testamento, «un pasaporte para el cielo» en palabras de Jacques Le Goff), le suministre la salvación eterna, diferenciándose de la actitud del santo y mártir porque estos últimos están más pendientes de los medios para conseguir la santidad (sufrimiento, tortura, caridad, predicaciones, conversiones, etc.) que en la finalidad en sí misma, que, por alguna circunstancia ignorada, estaba prácticamente asegurada. Se establecía así un modelo de ganancia eterna, inicialmente vinculado con los grupos nobiliarios, después impuesto al resto de la sociedad medieval mediante la cesión de bienes materiales al clero a cambio de una garantía salvadora. Esta era, fundamentalmente, la diferencia más palpable entre el comportamiento del santo y el resto de los mortales.

Mientras tanto, concluyendo ya el siglo XV, el moribundo se preocupará por su futuro más inmediato gracias a la divulgación de una forma específica de morir. Una muerte mal comprendida y peor aceptada arrastraba un sentimiento de inminente perdición del alma, aun después de la agonía. El arte de morir se centraba no en la muerte como entidad, sino en la situación del moribundo, en el postrer instante que contemplaba la elección entre la vida eterna y la condena en el infierno. La vida, que era continuo pecado como escribía Juan de Mena («Quien oyere mi tratado / a obrar bien se convida, / pues la Muerte non olvida / a ninguno mal pecado»), tenía irremediablemente que torcer su trayectoria para alcanzar el Paraíso. Así, el tránsito del creyente de la tierra al trasmundo estaba precedido por un ritual que imponía al enfermo las normas para alcanzar una muerte perfecta. El Bosco, al pintar la «Mesa de los pecados capitales» (Museo del Prado), consideró tanto la vida como el más allá. Una composición organizada en cuatro círculos centrales, con otros cuatro rodeando la primera esfera. La compensación entre Cristo surgiendo de la tumba y la advertencia del pintor («Cuidado, cuidado, el Señor lo ve») contrasta con los siete registros que representan los pecados capitales. Ira: reyerta entre el hombre y la mujer en el campo mientras un monje grita a la pareja. Envidia: comerciantes que miran con malos ojos a un noble que tiene un halcón en la mano. Avaricia: nobles que charlan entre sí. Gula: festín de tres individuos servidos por una mujer. Pereza: el burgués acomodado ante el fuego. Lujuria: escena campestre de nobles acompañados por juglares. Soberbia: la mujer que se contempla en el espejo. Los círculos menores situados en las esquinas del cuadro incitan a la reflexión ante los Quattuor hominum novissima. La muerte: un médico, tres religiosos y una monja acompañando al enfermo. En la cabecera de la cama aparecen un ángel, el demonio y la muerte, el esqueleto con una flecha, como en las Coplas de Manrique («Cuando tu vienes airada, todo lo passas de claro / con tu flecha», vv. 286-288) o en la Danza General («segura es tu muerte si doy en tirar / 
con esta mi flecha cruel que traspasa», vv. 7-8). Los familiares están al fondo en otra estancia. El Juicio: un modelo medieval, con Cristo triunfante con los ángeles sobre el Campo Santo del que surgen los difuntos. El infierno: las torturas de los hombres. La Gloria: un edificio palaciego con Cristo y los ángeles en diversos niveles. El arcángel san Miguel defiende a los difuntos mientras que san Pedro los recibe.

Hombres (y mujeres) que al morir esperaban, al menos, un lamento, un recuerdo. Desde el siglo XI se difunde en Castilla una tradición elegíaca, los llantos (planctus) y las endechas, composiciones poéticas con breves epitafios exaltando las virtudes del fallecido, relacionándole son los supervivientes e insistiendo en su pérdida. No es una consideración contemplativa sobre la muerte, sino una llamada al dolor por el difunto, en definitiva, por una persona totalmente ajena al escuchante. Desde el momento en que el planctus trata de reunir en un único momento la muerte real con el dolor ajeno, se convierte en una reflexión sobre la vida, una coacción hacia el hombre que siente también su propia muerte en la del héroe. Pero cualquier reacción ante la muerte es limitada -literariamente- en estos siglos, al menos hasta el siglo XIV. El esquema de la Plena Edad Media, al menos en los años situados en torno al año mil, es lo que Ariès ha denominado la «muerte domesticada». Hay un sentido individual, casi posesivo por parte del que sufre el óbito, a la vez que se subrayan unos rasgos ficticios, como ocurre en la lamentación de Carlomagno por la muerte de Roldán: «... ¡Muerto es mío sobrino, el buen de don Roldane! / Aquí veo atal cosa que nunca ví tan grande: / ¡Yo era pora morir, e vos para escapare!» (Cantar de Roncesvalles, vv- 8-10).

La anacrónica muerte de Roldán es una actitud común a los guerreros, una muerte que parece asumida por el héroe literario y no tanto por el rey, quejándose este último de su vejez aun inacabada frente a la juventud desaparecida. Una muerte natural o violenta que, en cualquier caso, no está tan dramatizada como en los textos de los siglos XIV y XV. Si Carlomagno se queja por Roldán, lo mismo hará Gonzalo Gustios, en el Cantar de los Infantes de Lara, cuando contempla las cabezas degolladas de sus hijos: «iMejor fuera la mí muerte / que ver tan triste jornada! / Al duelo que el viejo hace / toda Córdoba lloraba» (vv. 97-100). El elogio exagerado hacia el muerto se mantiene en la literatura medieval castellana, resaltando a menudo las virtudes y principios del noble, mientras que la propaganda aparece con frecuencia, siendo la muerte, para esta concepción caballeresca, un motivo de quejas y también de nuevas batallas: «Recuerden cristianos muy bien la su sangre: / por muerte de vno cient moros van delante. / De todos por ençima / vençe la morería en Iherusalem» (¡Ay Iherusalem!, estr. 17). La épica castellana en este sentido no se dirige exactamente hacia el sentido de la muerte, sino que en especial en los siglos XII y XIII ésta es reactivada siempre en función del personaje central, que da muerte pero también es capaz de llorar de pérdida de sus allegados. La Historia Troyana, texto escrito en torno al año 1270 según Ramón Menéndez Pidal, es ejemplar desde esta perspectiva. Héctor al dar muerte al rey Merión venga unos ultrajes, «ca quiero que fagades tanto que vayades luego agora 
tener compaña a los muertos» («Cómmo los griegos leuaron a los troyanos vencidos fasta la barrera e cómmo don Héctor mató al rey Merión»). El esquema de la muerte épica se reproduce de nuevo en los lamentos de Aquiles por Patroclo: « ¿quién cuydaría / que muerte nos partería / de non beuir vos conmigo / siempre mientre yo bebiere; / e que luego non moriese / yo, quando a vos viese muerto?» (Historia Troyana, Poesía I, vv. 22-27).

La muerte en sí misma, en los siglos XII y XIII, no es una realidad expresada gráficamente en los textos. Normalmente se llora al muerto, su desaparición y, fundamentalmente, los deseos y méritos que dejan en tierra. En esta misma perspectiva se sitúan los fallecimientos de nobles y reyes que aparecen en las crónicas.

«... E el infante don Sancho vínose para Salamanca, é adolesçió y muy mal, en guisa que fue desafuciado de los físicos, (...) era llegado a su muerte. (...) E cuando el rey don Alfonso vio en la carta que dicie que era muerto el infante don Sancho, su fijo, tomó muy grand pesar; é commo quier que lo non mostrase ante los que estaban ay, apartóse en una cámara solo, así que ome ninguno non osaba entrar a él, é comenzó a llorar por él muy fuertemente, é tan grande fue el pesar que ende avía, que decía por él muy doloridas palabras, diciendo muchas veces que era muerto el mejor ome que avía en su linaje. (...) «Maestre Nicolás: non lloro por mí, mezquino viejo, que pues él muerto es, nunca yo cobraré los mis reinos...» (...) E el infante don Sancho, seyendo en Salamanca desamparado de los físicos, quiso Dios que terminó su salud».

(Crónica del rey don Alfonso Décimo, LXXVII)

Un sentido específico en las manifestaciones de canto fúnebre ofrecen las «endechas». J.J. Alborg, F. Rico, A. Deyermond y otros especialistas han señalado que constituyen unas secuencias artificiosas a partir de unos esquemas repetitivos y específicos de la literatura medieval. No son populares, aunque sí en su forma de composición y transmisión. Transmitidas por la tradición judeo-española, las más antiguas son las realizadas a la muerte del rey Fernando III y del joven capitán Guillén de Peraza (año 1443). «Rey aventurado, / don Ferrando honrrado: / (...) Pero que eres fynado, / nunca serás olvidado: / por la muy gran nobleza / serás siempre loado, / e de las gentes deseado / por la tu gran ardidaza» (Endecha a la muerte de san Fernando).

\section{LAS ÚLTIMAS DISPOSICIONES DEL MORIBUNDO}

La comida después del entierro era una costumbre que estuvo ampliamente extendida y ha sido conservada hasta hace poco en algunas zonas rurales castellanas, al igual que la deposición de algunos objetos de valor en el féretro del difunto. El «pan de los pobres» o el «pan de la caridad» tenían asimismo su significado social. Quedan también los «prados de las ánimas» y los "carneros de las ánimas», animales que estaban exentos del pago de impuestos; el dinero procedente de su venta se destinaba a las ánimas benditas. El banquete funerario con- 
taba en el occidente europeo con una amplia tradición, pues la esperanza de los cristianos se ligaba a un vínculo de perenne comunión que se expresaba exteriormente con un banquete, el refrigerium, consumido en la Alta Edad Media en los alrededores de los sepulcros ${ }^{31}$. La ceremonia como tal se fue degradando, adquiriendo un carácter muy difuso, celebrándose especialmente en el mes de febrero la antigua fiesta en honor a los muertos, la llamada feralia o parentalia, la cara cognatio, que se exteriorizaba con banquetes, danzas y cantos licenciosos que contrastaban con el lugar (el sepulcro) y con el recuerdo doloroso de los familiares perdidos. Pero también esta costumbre se fue circunscribiendo al aniversario o al tercer año del fallecimiento, institucionalizándose ya desde el siglo XI todo este ritual funerario.

Hasta la llegada al camposanto se alargaba o menguaba el velatorio, un ritual interminable para los parientes y demasiado breve para otros: «los que son más propincos, hermanos e hermanas, / non coidan ver la ora que tangan las campanas» (estr. 1537a-b). Desde una perspectiva antropológica el velatorio tendrá un sentido más popular que estrictamente eclesiástico. Hay una serie de disposiciones sobre las costumbres y actitudes en los velatorios. Las prohibiciones eran frecuentes, lo que indica la extensión de ciertas prácticas funerarias. El cortejo fúnebre conducía al muerto al cementerio desde la aldea, colocado sobre unas parihuelas y cubiertos sus ojos por un paño; en otros casos, para vecinos más acaudalados, se tapaban los restos casi descompuestos por un lienzo blanco, de la villa o ciudad a la tumba, manifestándose una gran variedad de normas o rituales funerarios desde el siglo XIII. "Despesas fazen los omnes de muchas guisas en soterrar a los muertos, ca fazénlas en comprar los monumentos e aun en fazerlos e otrossí en leuarlos a soterrar e mayormiente quando mueren fuera de sus logares e los han alla a leuar e por guardarlos de noche o de día quando no pueden soterrarlos tan ayna e en candelas e en mortajas e en todas las otras despesas que fazen por razón del cuerpo ante que sea soterrado" (Primera Partida, XIII, XV'). Normalmente, después del velatorio seguían las exequias centradas en torno a la liturgia de difuntos, si bien los textos no se tomaban de los oficiales sino de los documentos no canónicos como el «IV Libro de Esdras», donde aparecen constantemente la luz y el descanso como prototipos de un «paraíso». En cualquier caso, ante el cuerpo se rezaban tres nocturnos y otros tantos responsos por un clérigo que estaba acompañado por el sacristán con la cruz. Tras los oficios el cadáver era sacado de la iglesia, con cierta formalidad, pues (excepto el del clérigo) era conducido mirando a oriente. La carga simbólica de estos acontecimientos es palpable: la procesión al Campo Santo es el retorno a la tierra, un «eterno retorno» figurado. Mientras tanto, los eclesiásticos eran los elementos privilegiados en cuanto a las donaciones post mortem y testamentos, sus funciones eran precisas aunque no siempre cumplidas: «non dan por Dios a pobres ni cantan sacrificios, / nin dizen oraçiones nin cumplen los ofiçios...» (estr. 1540a-b). "Ca diz que no ha tan buen ofiçio / commo de sacrificio, / de salterios rezar / e de misas cantar» (Elena y Ma-

${ }^{31}$ O. GIORDANO, Religiosità popolare nell'Alto Medioevo, Bari, 1977, pp. 167-168. 
ría. Disputa del clérigo y el caballero, vv. 356-360) ${ }^{32}$, incrementándose los bienes eclesiásticos por la celebración del trentanario de misas, llamadas también gregorianas, del papa Gregorio VII (1073-1085), que las instituyó y las enriqueció notablemente por el sufragio de difuntos, aunque, a veces, la viuda de buen ver cambiaba el trentanario por algún vecino más rico «o moço más valiente» (estr. 1542c).

La tradición pesaba de manera aplastante ante ciertos rituales de paso que enfrentaba al hombre con la «enemiga del mundo». En algunas ocasiones (disposiciones testamentarias, por ejemplo), hay una serie de bienes materiales que han de darse por el alma del difunto, teniendo en cuenta si éste murió o no sin parientes. Si el vecino moría «sin lengua» se establecía una distribución de los bienes: la quinta parte para el alma del fallecido, dividiéndola en tres porciones, un tercio para las obras eclesiásticas, otra para misas y la tercera para los pobres ${ }^{33}$. Del mismo modo está contemplada la muerte del hijo, pasando su herencia al padre o a la madre y, posteriormente, estableciéndose el «fuero de troncalidad» según el título 223 del Fuero de Salamanca.

Aparentemente, la práctica testamentaria no estaba demasiado extendida en la Castilla de la Edad Media. El papel ejercido por los testamentos es importante para comprender las actitudes mentales, por una parte, y los móviles económicos e ideológicos por otra. La inquietud por el pecado cometido, el temor a la muerte, la incertidumbre sobre el más allá, junto con el apoderamiento de los bienes por parte de los albaceas y las instituciones eclesiásticas son los rasgos más específicos de estos documentos. Los bienes materiales quedaban asegurados a cambio de la salvación del alma, aunque, anota Michel Mollat, el testador también perpetuaba la «consideración egocéntrica» del pobre por parte del rico, e incluso por los menos pobres ${ }^{34}$. Así pues, interesan los testamentos, en especial las invocaciones iniciales que van desde consideraciones genéricas sobre la vida y la muerte hasta fórmulas estereotipadas que pueden indicar la progresiva feudalización de la sociedad, abundando, por otra parte, las invocaciones trinitarias (In nomine Sancta et Indiuiduae Trinitatis...). Para el otro caso (consideraciones sobre la muerte), los ejemplos son numerosos y sintomáticos de una concreta ideología, bien sea por medio del redactor, bien por el sometimiento del moribundo o testamentario a las normas eclesiásticas de una «muerte canónica». El testamento deja traslucir unas razones, una mentalidad, una cultura determinada. Entre otras cosas, la preocupación por los bienes materiales suponía un impulso religioso para testar. Pero también se observa el miedo al infierno. El hecho de que aparezcan personajes como Datán y Abirón, Simón el Mago, el traidor Judas, o insospechadas y pecaminosas ciudades como Sodoma y Gomorra, ofrecía a la Iglesia la posibilidad de escenificar todo un mundo de amenazas providenciales para el moribundo cuando no cumplía con una buena muerte o cuando insistía en una desobediencia a las normas expresadas en el testamento.

32 R. MENÉNDEZ PIDAL, Textos medievales españoles. Ediciones críticas y estudios, Madrid, 1976, pp. 124-134.

${ }_{33}$ Así se recoge en el Fuero de Salamanca, en la edición de J. Sánchez Ruano, Salamanca, 1870.

34 M. MOLLAT, Les pauvres au Moyen Âge, París, 1978, p. 318. 
Tanto Juan Ruiz como otros autores denunciaron el poder que mostraba el dinero para asegurar la gloria eterna. Unas veces de forma irónica, otras bajo la forma de la indignación moral, el caso es que ya Alfonso XI en las Cortes celebradas en Alcalá de Henares en 1348 hizo aprobar unas leyes contra la amplia libertad que los religiosos disfrutaban para recibir herencias e intervenir en los testamentos de última hora.

\section{LA FAMA Y LOS MEDIOS DE INTERCESIÓN PARA LA SALVACIÓN}

Pero devedes saber que para ganar la gloria del Paraíso, que ha de guardarse omne de malas obras, que mester es de fazer buenas obras, e estas buenas obras para guardar las almas e guisar que vayan a Paraíso ha mester y estas quatro cosas: la primera, que aya omne fe e biva en ley de salvaçión; la segunda, que desque es en tiempo para lo entender, que crea toda su ley e todos sus artículos e que non dubde en ninguna cosa dello; la terçera, que faga buenas obras e a buena entençión porque gane el Paraíso; la quarta, que se guarde de fazer malas obras porque sea guardada la su alma de ir al Infierno.

(Don Juan Manuel, El Conde Lucanor, Quinta parte)

La destrucción de los dones físicos era imperdonable. Paulatinamente, en el mundo medieval, se pasará del horror causado por la muerte a la meditación sobre la ausencia de la vida y el amor. Pero todavía no se ha llegado a embellecer lo que en sí es intrínsecamente desagradable y repugnante. ¿Por qué? La vida todavía es frágil, caduca. La vanidad de esa vida es repetitivamente reseñada por numerosos autores, un tema constante en la literatura desde la Antigüedad. La vida se presentará como una partida de dados o ajedrez, como un juego en el que ninguno de los participantes se dejará vencer. La vida como azar y la muerte como dura prueba. Claro que el hombre está condenado al fracaso, recurriendo entonces los escritores a un tópico, la vanidad de la vida: Vanitas vanitatum, dixit Eclesiastés; vanitas vanitatum, et omnia vanitas (Eccl. 1, 2), que con el bíblico Ubi sunt qui ante nos in hoc mundo fuere? y toda la tradición medieval sobre la muerte darán como resultado una meditación sobre la fugacidad de cosas y seres, con una contemplación positiva o negativa según los casos. A menudo, el problema se resolvió en el contemptu mundi, en la actitud de desprecio ante el mundo y la vida que provocarán un tétrico memento mori. El mundo es considerado en el tratado de Inocencio III De contemptu mundi enemigo del alma, siendo la muerte la liberadora por significar el acceso a una nueva vida. La actitud meramente contemplativa de los santos de Gonzalo de Berceo adquiere un tono bien distinto a partir del siglo XIV, cuando nace tímidamente el sentido trágico de la muerte, si bien no hay que relacionar tanto esta modificación con un accidente coyuntural (la Peste $\mathrm{Ne}$ gra, por ejemplo) como en un conjunto de circunstancias que afecta a los hombres, a su miedo, estado de nerviosismo, anhelos religiosos y supervivencia material ${ }^{35}$. Las

35 «Las representaciones de la muerte afirman potentemente, en el final de la Edad Media, la fe en la vida terrestre, exaltan la dignidad humana y plantean el eterno problema de ese lazo inexplicable entre el aniquilamiento del cuerpo y la esperanza de la vida eterna: ¿la tierra, el cielo, el infierno o... nada?», J.-L. GONGLIN, Les misérables dans l'Occident médiéval, Paris, 1976, p. 213. 
nuevas condiciones sociales provocarán cierto cambio, al menos cierta ruptura con la tradición castellana de los siglos XII y XIII, con una literatura que hacía creer aparentemente que «el espíritu del hombre medieval, enemigo del mundo siempre, se encontraba a gusto entre el polvo y los gusanos " ${ }^{36}$. Polvo y gusanos, o descomposición del cuerpo. Los ricos, en este caso, tenían escasas ventajas sobre los pobres, aunque no ocurría lo mismo con la cuestión de la fugacidad de la vida, pues desde finales del siglo XIII algunos grupos privilegiados pondrán el acento en los valores más tangibles de la vida, aunque sean valores que terminarán destrozados por la propia muerte, «el bien de aqueste mundo la muerte lo destaja, / fallecen los dineros, el oro, la plata, / el pres e la bruneta, verdescur e escarlata» (Proverbios en rimo del sabio Salomón, rey de Israel, vv. 17-20), pero que pueden tener una utilidad en vida para el bien morir, para alcanzar la salvación eterna gracia a la hacienda. De todas formas, la muerte del rico era más cara o más costosa en términos económicos que la del pobre, que no tenía nada que perder.

E aquel genoués adolesçió muy mal, e de que entendió que non podía escapar de la muerte, fizo llamar a sus parientes e a sus amigos; e desque que todos fueron con él, envió por su muger e sus fijos: e assentosse en un palaçio muy bueno donde paresçía la mar e la tierra; e fizo traer ante sí todo su tesoro e todas sus joyas, e de que todo lo tovo ante sí, començó en manera de trebejo a fablar con su alma a esta guisa:

- «Alma, (...) e pues tu as tanto bien e non te tienes ende por pagada nin puedes sofrir el bien que tienes, pues con todo esto non quieres fincar e quieres buscar lo que non sabes, de aquí adelante ve con la ira de Dios, e será muy nesçio que de ti se doliere por mal que te venga.

(Don Juan Manuel, El Conde Lucanor, Exemplo IV)

\begin{abstract}
Monges, clérigos e fraires, que aman a Dios servir, si varruntan que el rico está ya para morir, quando oyen sus dineros que comiençan reteñir, quál d'ellos lo llevará comiençan luego a reñir.
\end{abstract}

(Libro de Buen Amor, estr. 506)

El dinero, en el Arcipreste, es el creador y transformador de las condiciones sociales, hombres y destinos de las almas. Ese dinero ejerce un papel fundamental no sólo en la vida terrenal, sino también a la hora de la muerte, en especial en ciertos actos litúrgicos, aniversarios, funerales, etc. En general, el tema de la vanidad y fugacidad de la vida es repetitivo hasta la saciedad. Los lamentos son expresiones de unas ideas religiosas imbuidas de cierto pesimismo laico. Queda la actitud del hombre ante esas preguntas sin respuestas.

Como diz' Salomón, e dize la verdat, que las cosas del mundo todas son vanidat, todas son pasaderas, vanse con la edad,

36 J. HUIZINGA, El otoño..., op.cit., I, p. 204. 
salvo amor de Dios, todas son liviandad.

(Libro de Buen Amor, estr. 105)

Pensando yo en la vida, deste mundo mortal, que es poca e peligrosa, llena de mucho mal.

La nuestras mezquindades ¿quién las podría contar?

Que en el mundo sofrimos, ¿quién lo podría callar?

Por ende muy mejor es de lo declarar,

porque nos de los yerros podamos avisar.

Si bien pensamos finsia de santidad,

en esta vida presente todo es vanidad.

(P. López de Ayala, Rimado de Palacio, estr. 7a-b, 1531, 1534a-b)

\author{
Cómo se passa la vida; \\ cómo se llega la muerte \\ tan callando... \\ Cómo, a nuestro parecer, \\ cualquiera tiempo passado \\ fue mejor... \\ Partimos cuando nacemos, \\ andamos mientras vivimos, \\ e llegamos \\ al tiempo que fenecemos, \\ assí que cuando morimos, \\ descansamos. \\ (J. Manrique, Coplas..., vv. 4-6, 10-12, 55-60)
}

La dolorosa e acelerada muerte del rey don Alonso debe ser asaz cierta prueba a todos los mortales de la vana e poca firmeza de las cosas deste mundo y de las cosas del nuestro rey don Alonso.

(D. de Valera, Memorial..., XLI)

La muerte, a pesar de todo, tenía un fuerte componente discriminatorio en función de la pertenencia del fallecido a un determinado grupo social. El óbito del caballero, noble, rey, obispo o cardenal está en muchos casos atenuada por unas posteriores circunstancias artísticas. Su poder se reflejará en la tumba levantada en una capilla funeraria. Así que la muerte del héroe no será solo un lamento pétreo, sino la tipificación de una manera de dejar el mundo, o dejar de ser, pues el caballero sigue presente en la sociedad exaltado y mantenido por una tradición colectiva vinculada a los grupos dirigentes.

La propaganda mortuoria o funeraria tendía a confundir algunos elementos, equiparando al noble con el santo, la muerte violenta con la martirial. Una reciprocidad entre el sentido de la muerte y estatus social del difunto parece apreciarse tanto en la literatura como en el arte. Incumpliendo cualquier normativa acerca de los novissima hominis (la muerte y el juicio particular), el héroe accede directamente al cielo, se asume la muerte violenta al estilo de los mártires («El que aqui muriere lidiando de cara / prendol yo los pecados e Dios le abra el alma», Poema 
de Mío Cid, vv. 1704-5) o se ignora la presencia de la muerte en Rodrigo Díaz de Vivar, un santo laico y un héroe épico. En este último caso, la influencia de los rituales sobre la muerte se aprecia en el Poema en la amplia oración de doña Jimena (vv. 330-365), interpretada hace años por Leo Spitzer ${ }^{37}$ como una derivación paralela de las viejas oraciones mágicas cristianas que subsistían en el Ordo commendationis animae, contestada luego por Peter $\mathrm{E}$. Russell al insistir en que la liturgia de la época no ofrecía formas especiales de oración, sino que el reconocimiento al muerto se efectuaba por una memoria externa: la oración de Jimena «no podía ser, pues, una sencilla versión en lengua vernácula de ninguna forma litúrgica o paralitúrgica latina que realmente existiera, sino una forma inventada que, para satisfacer las necesidades de verosimilitud, basándose en reminiscencias de la liturgia (y de otras formas de culto consagradas), intenta trasmitir la impresión de que es lo que no es: una auténtica oración» ${ }^{38}$. Por otra parte, desde el siglo XII numerosas obras castellanas reivindican el papel de la oración como medio para asegurar el tránsito feliz a la otra vida. Por ejemplo, la oración de Teófilo (Milagros de Nuestra Señora, XXIV) es una forma de intercesión para asegurar la salvación («Señora -disso-, valas a la alma mesquina...»), alejándose de las oraciones de los moribundos que pueden salpicar el Ordo commendationis animae. En el mismo sentido de lejanía hacia esa liturgia se encuentra la oración de súplica realizada de forma colectiva en el Poema de Fernán González (vv. 105-113). Al igual que el Cid («que Dios le curie de mal», v. 365), el santo está protegido por la divinidad. Se llegaba así a la coerción hacia la divinidad, pues era la salvación lo que interesaba, no tanto el medio. Para una finalidad, nada mejor que recordar la victoria del Hijo sobre la muerte:

\author{
En el monumento resuçitest, \\ fust a los infiernos commo fue tu voluntad, \\ quebrantaste las puertas e saqueste los santos padres. \\ Tu eres rey de los reyes... \\ (Poema de Mío Cid, vv. 358-361) \\ Mucho fue la muerte bien aurada \\ porque fue restaurada, \\ e si Él non muriesse \\ non es home que Parayso houiesse; \\ mas por la muerte fue Él tan forçudo \\ por quel diablo es vençudo: \\ el muerto vençió al matador \\ e finco el falso por traydor. \\ (Vida de Santa María Egipciaca, vv. 566-573)
}

Se estaba muy lejos de las situaciones litúrgicas relacionadas con el Ordo..., en las que el fin primario era la oración por los moribundos. Continuará esta tradi-

37 L. SPITZER, «Sobre el carácter histórico del Cantar de Mío Cid», Nueva Revista de Filología Hispánica, II (1948), p. 117 (105-117).

38 P.E. RUSSELL, «La oración de doña Jimena (Poema de Mío Cid)», en Temas de 'La Celestina' y otros estudios (Del Cid al Quijote), Barcelona, 1978, p. 153. 
ción de las oraciones de súplica en el Arcipreste (estr. 1-2) y Pero López de Ayala en el Rimado (vv. 769-780: «... que deste grand dolor... sea por Tí librado»). Los autores en estos casos interceden no por una cuestión abstracta, pues los dos se encuentran en sendas cárceles alegóricas: «sácame d'esta lazería, d'esta presión mesquina», «libra a mí, Dios mío, d’esta presión do yago», "Señor, de aquesta coita saca al tu Açipreste» (estr. $2 d, 3 d, 6 d$ ). En cualquier caso hay que ver en estas oraciones la manifestación de una devoción hacia la Virgen y, en general, hacia todos los santos, precisándose así de unos medios recíprocos de interacción. Unos poderes mutuos que se contraían también a la hora de matar. La muerte era violenta en las múltiples ocasiones que tenían los grupos superiores para enfrentarse a un supuesto enemigo. Así, la religiosidad del momento histórico, circunstancial, dependía de la clase social, al igual que cada individuo provocaba una determinada muerte según se actuara como verdugo o se sufriera como fallecido.

\author{
El que aquí muriere lidiando de cara \\ prendol yo los pecados e Dios le abra el alma. \\ A vos, Çid don Rodrigo - ien buen ora çinxiestes espada!
}

(Poema de Mío Cid, vv. 1704-1706)

\begin{abstract}
E quando esto vido el arrayaz Aben-Maçar, dióle las espuelas al caballo, el fue al arçobispo donde estaba desnudo e dióle con una azagaya por encima del ombro, que le entró al cuerpo, e matolo. E dijo: «Non quiera Alá que por un perro se maten tantos buenos commo aquí están». E cortáronle la cabeça e la mano en que tinie el anillo, e movieron ende con su presa, e fuéronse.
\end{abstract}

(Crónica del Rey Don Alfonso Décimo, LXIII)

Aunque habitualmente se diferencia en cualquier estudio sobre hagiografía, caballería, mentalidades y actitudes ante la muerte una distinta forma de alcanzar el más allá, de enfrentarse con el "sieglo mayor» (Libro de Alexandre, v. 2067d), en definitiva de traspasar el fino umbral entre la vida y la muerte por parte de santos y mártires, nobles y clérigos, reyes, campesinos y rústicos, en realidad todos parecen imitar un modelo común, el de la «muerte canónica» citada por Ariel Guiance ${ }^{39}$. Así pues, monarcas, nobles y clérigos se acomodan a la muerte del santo, éste al óbito establecido eclesiásticamente y el resto de la población a los imperativos de una cultura clerical a veces más impuesta por una coacción material que por una propaganda extraeconómica. La verdad es que moría mejor quien más aceptable o resignadamente aceptaba su fin siguiendo los rituales característicos de una supuesta perfecta agonía. Beati mortui qui in Domino moriuntur. Amodo iam dicit Spiritus, ut resquiescant a laboribus suis: opera enim illorum sequuntur illos (Ap. 14, 13). «Dichosos desde ahora los muertos que mueren en el Señor. De seguro, dice el Espíritu, podrán descansar de sus trabajos, porque van acompañados de sus obras».

${ }^{39}$ A. GUIANCE, Los discursos sobre la muerte en la Castilla medieval (siglos VII-XV), Valladolid, 1998, p. 101. 
Exceptuando la literatura de algunas fuertes personalidades medievales (Juan Ruiz, Jorge Manrique o Juan de Mena), los discursos sobre la muerte mantienen cierta uniformidad a partir del ideal utópico de la sequela Christi. Una diferencia sí que se mantiene desde el instante en que el santo no necesita invocar a Dios, a la Virgen o a los santos para alcanzar la llamada plenitud eterna, mientras que, más terrenales e inmediatos, otros individuos insisten en implorar a los intermediarios santos para alcanzar la salvación. La tradición de las oraciones de súplica, en algunas ocasiones procedentes del «Ritual de los Agonizantes», aparece tanto en Gonzalo de Berceo como en el Poema de Fernán González, continúa en el Arcipreste de Hita (Libro de Buen Amor, vv. 1-10) y con Pero López de Ayala en el Rimado de Palacio (vv. 769-780). Los medios de interacción son mutuos, recíprocos, por lo que el moribundo ruega ante la Virgen y los santos.

Al final quedaba la fama del difunto, el de un cuerpo que había sido un «terrón de tierra" y que, vivo o muerto, podía haber caído en la honra o en la deshonra. Con las modificaciones registradas desde el siglo XIV, caracterizadas por el alejamiento de las cualidades santas, por el progresivo olvido del óbito del elegido por Dios, se empieza a vislumbrar un nuevo sentido de la muerte, la «One's own Death» según la terminología de Ariès, un fallecimiento centrado en el propio cuerpo bajo la contemplación ajena. Una visión de la muerte que, en el caso castellano, pasa de la simplicidad de la poesía épica, concentrada en lamentos más o menos artificiosos sobre la muerte ajena, a una sensibilidad hacia la vida terrena y social, una representación del juicio propio y del Juicio Final y un leve surgimiento de la temática macabra desarrollada alrededor de la descomposición física, una personalización de la propia muerte que culminará con la exagerada consideración de la fama/honra como estructura mental nobiliaria desde finales del siglo XIII, como un valor inicialmente aristocrático que se extiende en Castilla al resto de la sociedad de forma descendente ${ }^{40}$. La accidentalidad del cuerpo y su asociación forzosa con un alma inmortal incidía en la aparición de la muerte moral durante la vida del personaje en cuestión. Los ideales de la nobleza se hacía presentes en la sociedad medieval, marcándose la nítida diferencia entre la verecundia y la inverecundia, la honra que era "como adelantamiento señalado con loor que goza ome por razón del logar que tiene» (Segunda Partida, XIII, XVII ) y la deshonra, pues «después que es enfamado, maguer non aya culpa, muerto es quanto al bien e a la honra deste mundo" (Segunda Partida, XIII, IVª). En la Edad Media había dos sistemas de conceptuar la honra y el honor, uno que arrancaba de unos principios filosóficos, religiosos y jurídicos, otro que procedía de situaciones de hecho, de la propia complejidad social. Como afirmaba Julio Caro Baroja, fue peregrina la forma como se ajustaron los dos modelos, demostración plena también de que el principio de la

40 La honra personal es «un valor hecho de orgullo y vanidad, (...) un lugar común, el objeto de una lucha entre las clases que van a modelar su imagen en función de ese lugar común y van a intentar actuar sobre él redefiniéndolo a partir de las posibilidades que brinda», M. MADERO, Manos violentas, palabras vedadas. La injuria en Castilla y León (siglos XIII-XV), Madrid, 1992, pp. 27 y 201. 
relatividad en la contradicción no rige en la vida de las sociedades sino que en la contradicción misma está el ser de las cosas, como pretendería un hegeliano ${ }^{41}$. No es de extrañar, pues, que aparezcan numerosas disposiciones en cuanto a la deshonra: por el homicidio cuando se empareja la muerte con la pérdida de la honra, o por el insulto, normalmente asociado a prácticas consideradas obscenas. En general, los hombres que carecían de honra eran aquellos considerados como ladrón, preso, querelloso, desafiador, «cativo» (pobre, desvalido), enemigo, alevoso, traidor, deudor, cornudo, «fudid in culo» (sodomita), «gafo» (leproso), etc. "Cualquier home que a otro demostrase, e le dixere gafo, o sodomético, o cornudo, o traydor, o herege, o a su muger de su marido puta, desdígalo ante el alcalde y ante homes buenos al plazo que él pusiere ante el alcalde: e peche trecientos sueldos, la meitad al rey y la meitad al querelloso; e si negare que lo no dixo, e non gelo pudiere probar, sálvese así como manda la ley; e si salvar no se quisiere, faga la enmienda e peche la calumnia» (Fuero Real de España, IV, IV, II ${ }^{\mathrm{a}}$ ). Claro está que no sólo las deudas, las querellas y los ultrajes conducían a la mala fama, sino que, en un amplio espectro tradicional, procedente de la consolidación de los fueros municipales, el sexo y sus derivaciones sórdidas eran objeto de la deshonra. Cualquier forma de sexualidad mal encaminada era prueba de «desvergüenza»42, o cualquier hecho que pudiera provocar un escándalo, como el cuerpo desnudo, el permanecer en la calle después del toque de la campana o el propio juego ${ }^{43}$.

A medida que se incrementaba el valor de la honra desde principios del siglo XIV, los nobles disfrutaron de unas mayores garantías para salvar el alma, en detrimento de los campesinos que, en principio, quedaron un tanto marginados del uso y abuso del purgatorio, una noción compleja que encierra una reflexión teológica de las elites dominantes que se sitúa en un plano intermedio entre el cielo y el infierno, «una provincia reconquistada por las concepciones precristianas de la muerte ${ }^{44}$. Al mismo tiempo, algunos miembros de la aristocracia castellana se obsesionaron por su honra y, al tiempo, por la salvación del alma, llegando incluso a escribir algún libro para que los hombres «fuessen más allegados a la carrera porque pusiesen salvar las almas» (El Conde Lucanor, Prólogo), preocupándose don

41 J. CARO BAROJA, «Honor y vergüenza (Examen histórico de varios conflictos populares)», Revista de Dialectología y Tradiciones Populares, XX (1964); reimpr. en La ciudad y el campo, Madrid, 1976, pp. 63-130.

42 Desde el impúdico acto de «meter mano» («Nengún omne que metier mano en clérigo por mala voluntade...») hasta la violación o el adulterio de la mujer (»Todo omne qui mugier uilda premier, o manceba aforcia o a virto, fírmelo con dos alcaldes que se cieno trascando a fuero, e iúrelo don doze vecinos...», Fuero de Salamanca, 333 y 227). «E si ella dexare a su marido, sea deseredada; e qui la anparar, peche diez maravedís a su marido quantos días alla trasnochar, en casa del pariente o del que la anparar», Fuero de Coria, I. 64. «Estar sola con vos solo, esto yo non lo faría, / non deve muger estar sola en tal conpañía: / naçe dende mala fama e mi desonra sería; / ante testigos que veyan, flabarvos he algund día», Libro de Buen Amor, estr. 681.

43 «Qui despojare ome e lo dexar en cuero, pechel dos maravedís, si ge lo pudier firmar; e si non jure (con) un vezino», Fuero de Coria, II, 54. «Todo ome que de noche andar por la villa, desque la canpana dexaren de tanner, e non dixier onde vien, ho onde va, o lo non provar por buenos omes que es de buena fama, fáganle como a ladrón», Fuero de Coria, I, 236. «Todo omne que iugar tablas o dados enfórquenlo», Fuero de Salamanca, $31^{\circ}$.

${ }_{44}$ G. DUBY, Le temps des cathèdrales. L'art et la société, 980-1420, Paris, 1976, p. 285. 
Juan Manuel no tanto por la muerte en sí, sino por la fama imperecedera, el mito de la gloria, tras una muerte inexcusable: «Petronio, porque yo se que la muerte non se puede escusar, querría fazer en guisa que después de mi muerte, que dexasse alguna cosa señalada que fincasse por mi alma e que fincasse para siempre, porque todos sopiessen que yo feziera aquella obra» (El Conde Lucanor, Exemplo XL). Gloria alcanzada, sin duda, gracias a la limosnas y oraciones. La salvación estaba asegurada. «E él avía mandado mucho por su alma. E porque fue tan bien complido e tan aína, estavan los fraires muy pagados e en muy buena entençión e buena esperança de la su salvaión» (El Conde Lucanor, Exemplo XL).

La muerte, porque estaba presente, llenaba de inquietudes a los hombres y mujeres. Parece difícil creer en el desdén del castellano hacia la muerte, o que los castellanos, como afirmaba Sánchez-Albornoz, habían sido educados en el desprecio de la muerte, exaltándola y afirmando un fallecimiento con un matiz martirial. Sin embargo, acentuadamente desde el siglo XIV el óbito personal se conjuga con la honra y el honor:

'Murió el onbre e murió el su nombre'; mas si quisiéremos olbidar los viçios e fazer mucho por nos defender e levar nuestra onra adelante, dirán por nos después que muriéremos: 'Murió el onbre, mas non murió el su nombre'. E pues viziosos e lazdrados, todos avemos de morir, non me semeja que sería bueno si por viçio nin por la folgura dexáramos de fazer en guisa que después que nos muriéremos, que nunca muera la buena fama de los nuestros fechos.

(Don Juan Manuel, El Conde Lucanor, Exemplo XVI)

Más tarde, en la segunda mitad del siglo XV un sentido panegírico y un componente didáctico-moral se presentará en las Coplas de Jorge Manrique, expresando no tanto la negación de la vida como la escala de los valores humanos, desde los más altos hasta las más bajas apetencias. Se cantará a un difunto en términos superlativos, con tantos elogios que, al final, el muerto parece deshumanizado para el propio lector, en un intento, señalaba hace años Pedro Salinas, «de abandonar a aquellos muertos muertos y sustituirlos con estos muertos vivos, por más paradójico que suene eso de vivificar a unos muertos. Manrique aparta la gran mascarada secular, las figuras ataviadas con toda clase de trapajería histórica deslucida, y erige esa breve galería de varones con hombres de su tierra, con semblantes conocidos y vestidos a la usanza de su tiempo" ${ }^{45}$. La muerte, al contrario que en otras obras citadas anteriormente, carece en Jorge Manrique de una presencia real y física, carece de una personalización, actúa como un visitante esperado y solemne al que Rodrigo Manrique espera en compañía de sus hijos y criados, una muerte no solitaria y enviada por Dios: «En la su villa d' Ocaña / vino la Muerte a llamar / a su puerta, / diziendo: 'Buen caballero, / dexad el mundo engañoso / e su halago" (vv. 394-399). La imagen del esqueleto viviente, o de la mujer con la guadaña, no existe en Manrique, ¿Dónde está la muerte? «Está sólo sobreentendida: es el trillador o el segador, o quizá el pesado buey que tan pronto

45 P. SALINAS, Jorge Manrique, o tradición y originalidad, Barcelona, 1974, p. 166. 
cortará o aplastará ciegamente esta vida. Jorge Manrique evita las comparaciones mecánicas y prefiere ahora sugerir la muerte como posibilidad no realizada de una imagen. La muerte, sombrío trillador o segador, es la causa no expresada de una destrucción no expresada, la tácita condición de nuestra nueva y agudizada consciencia de lo transitorio. Podemos percibirla, pero no la vemos» ${ }^{46}$.

Los ideales caballerescos del siglo XV sobreviven en la memoria y en el recuerdo de la vida del difunto, si bien ni la fama ni el honor son conceptos eternos: «pues otra vida más larga / de la fama glorïosa / acá dexáis. / Aunqu' esta vida d'honor / tampoco no es eternal / ni verdadera» (vv. 409-414). Pero las circunstancias históricas son determinantes para alcanzar la morada eterna, pues unos individuos han cometido en vida demasiados errores (Enrique IV) y otros han visto truncado su prometedor reinado (el infante Alfonso), deteniéndose el autor en la elegía funeral por el maestre de la Orden de Santiago, su padre, conciliando la consolación religiosa y el sentido de la fama, «esperad el galardón / que en este mundo ganastes / por las manos» (vv. 436-438). Parecidas consideraciones se localizan en el marqués de Santillana, ínigo López de Mendoza, con una concepción clasista en su observación de la realidad social y una visión de la muerte ligada a la fama y al infierno que merecen los que contravienen las normas que de la «misericordia fallaron", mientras que en Gómez Manrique únicamente se alcanzará la igualdad tras la muerte, cuando los tres órdenes sientan el peso de los pecados: «Llore conmigo la gente / toda de los tres estados, / pues por lavar sus pecados / mataron al inocente, / a mi Hijo y mi Señor, / mi redentor verdadero... / ¡Cuidata! ¿Cómo no muero / con tan extremo dolor? / ¡Ay dolor!» (Llanto por Nuestro Señor, vv. 35-43).

En resumen, la aceptación de una buena o mala muerte llevaba a los vecinos castellanos, feligreses de sus parroquias, a la aparente búsqueda de una protección de los santos y mártires, de sus reliquias y de otras formas de mediación que tutelaban el tránsito al más allá. En la sociedad del mundo medieval, las prácticas devotas, sin embargo, encubrían una gran variedad de experiencias vitales, unos resortes económicos traducidos en un montón de tierra o una sencilla losa en el cementerio exterior, o en una yacija granítica con su correspondiente epigrafía que recordara la memoria del difunto. Para una misma angustia ante la muerte, expresión del dolor en muchos casos, las formas simbólicas y los rituales de paso cambiaban sustancialmente, pues, de cualquier manera, tenían que adecuarse a la condición social y económica del difunto. Así pues, cuerpos corruptos de vecinos pecheros, artesanos, criados y criadas, pobres y mendigos, niños y niñas, menestrales, pegujaleros y hortelanos eran medianamente depositados en los alrededores de su iglesia parroquial, mientras que nobles caballeros, curas y canónigos y otros personajes ilustres de la sociedad castellana establecían mediante sus restos bajo losas un circuitus mortuorum en contacto subterráneo con los pavimentos sagrados y eclesiásticos.

46 S. GILMAN, «Tres retratos de la muerte en las Coplas de Jorge Manrique», Nueva Revista de Filología Hispánica, XIII (1959), p. 313 (305-324). 


\section{VI. «DE CÓMO MORIÓ TROTACONVENTOS E DE CÓMO EL}

ARÇIPRESTE FAZE SU PLANTO DENOSTANDO

E MALDIZIENDO LA MUERTE»: ORGANIZACIÓN LITERARIA

\section{A. Lamentación del autor (estr. 1520a-b)}

- Identificación de la Trotaconventos con la sabiduría femenina, «mataste a mi vieja».

B. Presentación y caracterización de la muerte (estr. 1520c-d-1525)

- Universalidad.

- Temor a la muerte, «enemiga del mundo»: mayor apego a las cosas terrenales.

- Dualidad y contraposición de personajes y actitudes: poder igualatorio de la muerte.

- Crueldad y falta de amor.

- Condición inexorable de la muerte, «non puede foir omne».

- Cuerpo y alma, tierra y muerte, fecundidad y vida.

- Fragilidad de la vida.

C. Presencia social de la muerte (estr. 1526-1531)

- Diálogo del autor con la muerte, reprochándola su presencia en el mundo.

- Poder igualatorio: «fazes al mucho rico yazer en grand pobreza».

- El cuervo como mensajero de la muerte, "que de ti s' farta».

- Dualidad ética-carnaval, lo moral-oficial y lo festivo: la presencia de la muerte.

B. Presentación y caracterización de la muerte (estr. 1532-1535)

- Fragilidad de la vida, acentuando su corta duración.

- ¿Concepción de la fama ante la muerte? Muerte física, pero no muerte social. O bien, sentido paródico del mito de la gloria humana.

- Desigualdad entre el bien y la moral.

- Consecuencias físicas de la muerte.

C. Presencia social de la muerte (estr. 1536-1543)

- Familia, herencia y agonía del enfermo.

- Aspectos litúrgicos: toque de campanas.

- La muerte y el muerto.

- Las exequias y otras maneras litúrgicas.

- Comida de difuntos: tradición popular.

- La herencia y la vida, el alma y Satán.

- Sufragios por el difunto.

- Personificación de la vida y la muerte.

B. Presentación y caracterización de la muerte (estr. 1544-1555)

- Incomprensión hacia la muerte.

- Aspecto físico de la muerte. 
- Dualidad belleza/fealdad.

- Juego de antítesis: dones y aberraciones.

- El mundo de la muerte, «el infierno profundo».

- Omnipotencia de la muerte.

- Dualidad basada en la fecundidad de la muerte.

- La religión cristiana motivada por el miedo a la muerte: «por tu miedo los santos fizieron los salterios».

D. Mecanismo de compensación y totalización (estr. 1556-1560)

- Muerte-Jesucristo/Eros masculino: «el Señor que te fizo».

- Principio de la fecundidad.

- La tradición evangélica.

- Población y despoblación, cielo e infierno: «fue por su santa muerte tu casa despoblada».

D. Otros mecanismos de compensación (estr. 1561-1564)

- Jesucristo como héroe que salva a los hombres escogidos.

D. Mecanismo de compensación y totalización (estr. 1564-1566)

- Otras hazañas de Cristo y el Paraíso.

- Invitación del autor para que Cristo le reserve un lugar en la gloria eterna.

- Magnificación de Dios frente a la muerte.

B. Presentación y caracterización de la muerte (estr. 1567)

- Nueva exaltación de Jesucristo y esperanza del poeta por burlar, gracias al primero, a la muerte, «a Dios me acomiendo».

- Tema del Ubi sunt?

A. Lamentación del autor (estr. 1568-1575a-b)

- Redención de la muerte.

- La muerte de Juan Ruiz por la muerte de la Trotaconventos.

- Santidad de la alcahueta, mártir por la divinidad, canonización y bendición sacerdotal: «con los mártires deves estar aconpañada».

- Propósitos del arcipreste: pago de las exequias y compromisos de oración. Súplica a las dueñas para que se lamenten por la pérdida que sufre el clérigo.

- Panegírico de la alcahueta.

E. Recomendación final (estr. 1575c-d)

- Oración.

- Nueva identificación de la vieja con el amor y el principio femenino.

F. Epitafio (estr. 1576-1580)

- Identificación de la muerta: «Urraca só que yago...».

- Llegada imprevisible de la muerte.

- Inexorabilidad de la muerte. 
- Invitación de la alcahueta a que el pueblo rece y no la maldiga, «un pater noster diga».

El que aquí llegaré, ¡si Dios le bendiga!, e ¡sí l' dé Dios buen amor e plazer de amiga! que por mí, pecador, un pater nóster diga; si decir no l' quisiere, a muerta non maldiga 